\title{
MicroRNA-34a targets epithelial to mesenchymal transition- inducing transcription factors (EMT-TFs) and inhibits breast cancer cell migration and invasion
}

\author{
Saber Imani ${ }^{1,2, *}$, Chunli Wei ${ }^{1,3, *}$, Jingliang Cheng ${ }^{1, *}$, Md. Asaduzzaman Khan ${ }^{1,4, *}$, \\ Shangyi Fu ${ }^{5}$, Luquan Yang ${ }^{1}$, Mousumi Tania ${ }^{1,6}$, Xianqin Zhang ${ }^{1}$, Xiuli Xiao ${ }^{7}$, Xianning \\ Zhang ${ }^{8}$, Junjiang $\mathbf{F u}^{1,3}$ \\ ${ }^{1}$ Key Laboratory of Epigenetics and Oncology, Research Center for Precision Medicine, Southwest Medical University, Luzhou, \\ Sichuan, China \\ ${ }^{2}$ Chemical Injuries Research Center, Baqiyatallah Medical Sciences University (BMSU), Tehran, Iran \\ ${ }^{3}$ State Key Laboratory of Quality Research in Chinese Medicine, Macau University of Science and Technology, Macau (SAR), \\ China \\ ${ }^{4}$ Faculty of Applied Sciences, Ton Duc Thang University, Ho Chi Minh City, Vietnam \\ ${ }^{5}$ The Honors College, University of Houston, Houston, TX, USA \\ ${ }^{6}$ Division of Computer Aided Drug Design, Red-Green Computing Centre, Dhaka, Bangladesh \\ ${ }^{7}$ Pathology Department, Southwest Medical University, Luzhou, Sichuan, China \\ ${ }^{8}$ Department of Cell Biology and Medical Genetics, Zhejiang University School of Medicine, Hangzhou, Zhejiang, China \\ *These authors have contributed equally to this work
}

Correspondence to: Junjiang Fu, email: fujunjiang@swmu.edu.cn, fujunjiang@hotmail.com

Keywords: microRNA-34a, thymoquinone, epithelial-mesenchymal transition, metastasis, breast cancer

Received: December 27, 2016

Accepted: January 25, 2017

Published: February 09, 2017

\section{ABSTRACT}

MicroRNA-34a (miR-34a) plays an essential role against tumorigenesis and progression of cancer metastasis. Here, we analyzed the expression, targets and functional effects of miR-34a on epithelial to mesenchymal transition-inducing transcription factors (EMT-TFs), such as TWIST1, SLUG and ZEB1/2, and an EMTinducing protein NOTCH1 in breast cancer (BC) cell migration and invasion and its correlation with tumorigenesis and clinical outcomes. Expression of miR-34a is downregulated in human metastatic breast cancers (MBC) compared to normal breast tissues and is negatively correlated with clinicopathological features of MBC patients. Ectopic expression of miR-34a in MBC cell-line BT-549 significantly inhibits cell migration and invasion, but exhibits no clear effect on BC cell growth. We found that miR-34a is able to inactivate EMT signaling pathway with mediatory of NOTCH1, TWIST1, and ZEB1 upon $3^{\prime}$-UTR activity in MBC cell lines, but has no inhibitory effects on SLUG and ZEB2. Furthermore, we investigated the synergistic effects of Thymoquinone (TQ) and miR-34a together on the expression of EMT-associated proteins. Results showed that co-delivery of $\mathrm{miR}-34 \mathrm{a}$ and $\mathrm{TQ}$ is able to inactivate EMT signaling pathway by directly targeting TWIST1 and ZEB1 in BT-549 cell line, indicating that they might be a promising therapeutic combination against breast cancer metastasis. Epigenetic inactivation of the EMT-TFs/miR-34a pathway can potentially alter the equilibrium of these regulations, facilitating EMT and metastasis in BC. Altogether, our findings suggest that miR-34a alone could serve as a potential therapeutic agent for $\mathrm{MBC}$, and together with $\mathrm{TQ}$, their therapeutic potential is synergistically enhanced. 


\section{INTRODUCTION}

From historical to contemporary science, metastatic breast cancers (MBC) have become one of the deadliest female malignancies worldwide with $>41,000$ deaths per year $[1,2]$. Despite significant progresses in clinical treatment strategies of $\mathrm{MBC}$, the 5-year survival rate after curative resection is reported to be only $\sim 24 \%$ [3]. Chemotherapy, radiotherapy and molecularly targeted therapy are the main components of MBC therapy [4]. The clinically heterogeneous nature of $\mathrm{MBC}$ relatively arises from its biological and genetic heterogeneity. Therefore, a better understanding of the genetic and molecular characteristics of $\mathrm{MBC}$ is warranted to decrease mortality and improve patient's quality of life [5]. A variety of genetic and epigenetic abnormalities characterizes the development of the metastatic process, where epithelial to mesenchymal transition (EMT) plays a vital, supportive role for local invasion, migration, growth, and drug resistance of breast cancer (BC) cells $[6,7]$.

EMT is characterized by the loss of epithelial cell polarity and tight cell-cell junction, such as E-cadherin and $\beta$-catenin, leading to the enhancement of the migratory and invasive attributes and the appearance of mesenchymal biomarkers, such as N-cadherin and vimentin [8,9]. EMT is modulated by different extracellular signals and several activating transcription factors, such as members of the SNAIL, zinc-finger E-box-binding (ZEB) and basic helixloo-helix (bHLH) families, including zinc finger protein SNAI2 (SLUG), Twist-related protein 1 (TWIST1), ZEB1 and ZEB2, which are master coordinators of EMT and the metastatic program [10-13]. The EMT-inducing transcription factors (EMT-TFs) induce EMT responses during tumor metastases by binding to the E-box sequences in the proximal promoter region of the repress epithelial genes and recruiting another post-translational modifications bio-machines $[9,10,14]$. In the early stages of MBC, EMT-TFs, like TWIST1, ZEB1/2, and SLUG, repress E-cadherin and $\beta$-catenin expression; promote EMT, cell motility and invasiveness; and permit the intravasation of tumor cells [15-18].

Recently, microRNA-34a (miR-34a) was identified as a novel class of tumor-suppressive miRNAs that is downregulated in several human cancers, including breast, lung, and liver; re-introduction of miR-34a mimics the inhibition of cancer cell growth and metastasis [19-21]. miR-34a resides on the chromosomal locus 1 p36.23 and is involved directly and indirectly with many different oncogenic processes, including growth, survival, differentiation, proliferations, migration, invasion, and immune responses [20]. Accordingly, overexpression of miR-34a acts as a mediator of tumor suppression by transcriptionally regulating TP53, NOTCH, and transforming growth factor beta (TGF- $\beta$ ) signaling pathways [14, 20, 22-25]. So far, it is unclear whether miR-34a epigenetically silences EMT by binding to
EMT-TFs in BC. Previous studies have shown that downregulation of TWIST1, SNAIL1, and SLUG has a key role in aggregating $\mathrm{MBC}$ treatment and increasing EMT-TFs levels correlated with poor prognosis in a MBC $[11,14,26]$.

Evidence implies that miR-34a is a promising non-invasive biomolecular tool for gene regulation in the metastatic process by coordinating TP53, NOTCH1, and TGF- $\beta$-pathways [27-29]. Since different cancer cell types display differences in the expression and relevance of EMT regulators [30-32], current attention is focused on systematically analyzing EMT-TFs' regulatory mechanism and EMT-TFs/miR-34a feedback loop, like the role of TWIST1, SLUG, ZEB1/2 and SNAIL1 in promoting BC migration, invasion and metastasis.

We aimed to investigate the role of miR-34a in human breast tumors with a focus on MBC. Here, we found that miR-34a potentially inhibits TFs, like TWIST1 and ZEB1, and EMT-associated protein NOTCH1 expression upon the 3 '-untranslated region (3'-UTR) in $\mathrm{BC}$ cells. Transient transfection of miR-34a significantly inhibits cell proliferation, cell migrations, cell survival and cell invasion of BC cell lines by targeting NOTCH1, ZEB1, and TWIST1. We have consequently revealed that miR-34a is downregulated in MBC tissues and suppresses cancer metastasis by affecting several malignancy endpoints.

\section{RESULTS}

\section{MicroRNA-34a expression in human BC cell lines and tissues}

Previous investigational screenings for miR-34a expressions in different tissues and cancer cell types found that the expression of miR-34a is variable in $\mathrm{BC}$ [30-32]. Therefore, we first measured the level of mature miR-34a in our collected MBC tissues and human BC cell lines using quantitative reverse transcriptase-PCR (qRT-PCR). Interestingly, the average level of miR-34a expression was consistently and significantly lower in tissues of MBC $(n$ $=33$ ) than that of normal breast samples $(n=15)$ (Figure 1A). In addition, miR-34a levels were significantly lower in some $\mathrm{MBC}$ cell lines in comparison to non-metastatic $\mathrm{BC}$ cell line MCF-7 (Figure 1B). There was no expression of the miR-34a in the MDA-MB-435 BC cells. The above data showed that miR-34a is significantly downregulated in MBC tissues, suggesting that the downregulation of miR-34a most likely affects the progression of MBC.

\section{MicroRNA-34a expression correlates to clinicopathological features}

The demographic and clinical characteristics of the 48 subjects were showed in Table 1 . The mean ages of these patients were $46.34 \pm 9.71$ (age range, 26-67 years). 
There was no statistically significant difference between the groups in terms of age and number. The relative expression of miR-34a in MBC tissues was significantly related to certain clinicopathological features, like progesterone receptor and $\mathrm{Ki}-67$ proliferation marker status. Furthermore, miR-34a expression levels were inversely correlated with Ki-67 $(r=-0.23, P=0.002$; Figure 1C). Figure 1D presents a positive correlation between the miR-34a expression level ratios and PR. However, clinicopathological features, such as human epidermal growth factor receptor-2, estrogens receptor, and TP53, did not exhibit a significant association with miR-34a expression (Supplementary Figures 1A-1C). In general, a significant correlation between miR-34a
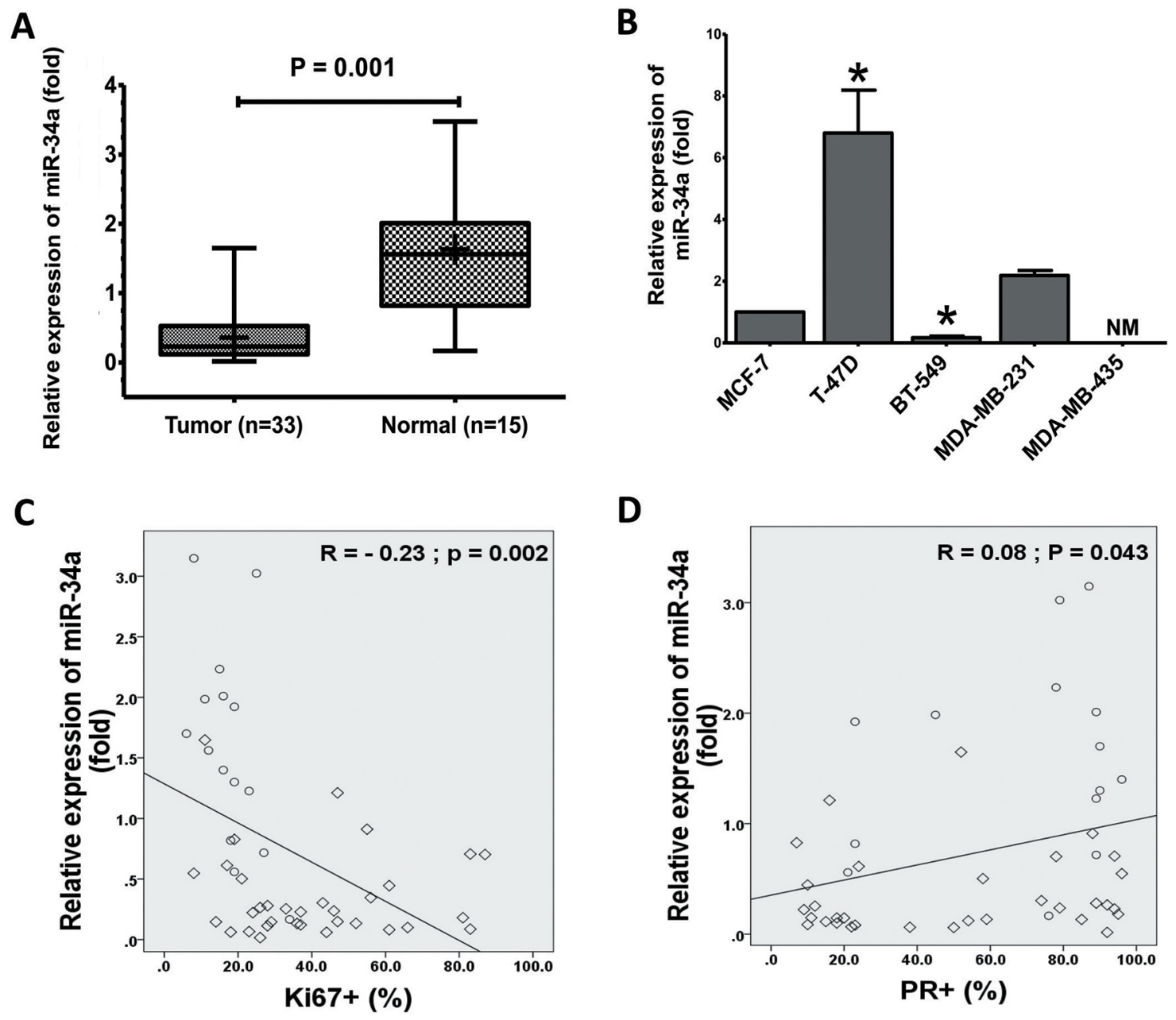

Figure 1: Expression of miR-34a in BC cell lines and BC specimens. A. The expression levels of miR-34a in normal breast significantly decreased in human cancer tissues that measured by TaqMan ${ }^{\circledR}$ MicroRNA assays kit. B. Total RNA was prepared from the cell lysates and expression of miR-34a was quantified by TaqMan MicroRNA Assays. The expressions of miR-34a was normalized against the expression level of U6 snRNA. The expression levels T-47D, BT-549, MDA-MB-231, and MDA-MB-435 were expressed as relative to the miR-34a expression level of MCF-7 cells, non-metastatic BC cell lines (mean $\pm S D$ ). Inverse relationship between levels of miR-34a in 48 human breast specimens with Ki67 C. PR expression D. The diamond indicates human BC specimens (n=33), and circles represent paired adjacent normal tissue $(n=15)$. Data were analyzed by Spearman's rank correlation coefficient. In general, it was observed significant correlation between the miR-34a expression levels and some clinicopathological features of MBC patients. Data presented is a representative of three different experiments. (NM, No measured value; $* P<0.05$ ). 
Table 1: Relationship between miR-34a expression level and clinicopathological features of MBC patients

\begin{tabular}{|c|c|c|c|}
\hline \multirow{2}{*}{$\begin{array}{l}\text { Demographic and } \\
\text { Histopathologic variables (n) }\end{array}$} & \multicolumn{2}{|c|}{ miR-34a expression levels } & \multirow{2}{*}{ P value } \\
\hline & $\operatorname{miR}-34 a^{+}(\geq 0.74)$ & $\operatorname{miR-34a^{-}(<0.74)}$ & \\
\hline Subjects (\%) & $17(35.4)$ & $31(64.6)$ & 0.001 \\
\hline \multicolumn{4}{|l|}{ Age (yrs.) } \\
\hline$<$ mean $(27)$ & $10(20.8)$ & $17(35.4)$ & \multirow{2}{*}{0.517} \\
\hline$\geq$ mean $(21)$ & $7(14.6)$ & $14(29.2)$ & \\
\hline \multicolumn{4}{|l|}{ Tumor histology } \\
\hline Ductal (30) & $3(9.1)$ & $27(80.1)$ & \multirow{2}{*}{0.238} \\
\hline Lobular (3) & $1(3.0)$ & $2(6.1)$ & \\
\hline \multicolumn{4}{|l|}{ Tumor Size } \\
\hline$\leq 3 \mathrm{~cm}(4)$ & $2(6.1)$ & $2(6.1)$ & \multirow{3}{*}{0.08} \\
\hline $3-9 \mathrm{~cm}(24)$ & $2(6.1)$ & $22(66.6)$ & \\
\hline$\geq 9 \mathrm{~cm}(5)$ & $0(0)$ & $5(15.2)$ & \\
\hline \multicolumn{4}{|l|}{ Diagnosis stage (TNM) } \\
\hline Stage II (15) & $0(0)$ & $15(45.5)$ & \multirow{2}{*}{0.075} \\
\hline$\geq$ Stage III (18) & $4(12.1)$ & $14(42.4)$ & \\
\hline \multicolumn{4}{|l|}{ Node status } \\
\hline Negative (26) & $3(8.6)$ & $23(65.7)$ & \multirow{2}{*}{0.162} \\
\hline Positive (9) & $3(8.6)$ & $6(17.1)$ & \\
\hline \multicolumn{4}{|l|}{ Neoadjuvant therapy (\%) } \\
\hline Yes (12) & $3(9.4)$ & $9(28.1)$ & \multirow{2}{*}{0.399} \\
\hline No (20) & $3(9.4)$ & $17(53.1)$ & \\
\hline \multicolumn{4}{|l|}{ Chemotherapy } \\
\hline Yes (14) & $3(9.4)$ & $11(34.4)$ & \multirow{2}{*}{0.541} \\
\hline No (18) & $3(9.4)$ & $15(46.9)$ & \\
\hline \multicolumn{4}{|l|}{ PR } \\
\hline Negative (22) & $6(12.5)$ & $16(33.3)$ & \multirow{2}{*}{0.02} \\
\hline Positive (26) & $11(22.9)$ & $15(31.2)$ & \\
\hline \multicolumn{4}{|l|}{ ER } \\
\hline Negative (18) & $4(8.3)$ & $14(29.2)$ & \multirow{2}{*}{0.121} \\
\hline Positive (30) & $13(27.1)$ & $17(35.4)$ & \\
\hline \multicolumn{4}{|l|}{ P53 } \\
\hline Negative (34) & $13(32.5)$ & $21(52.5)$ & \multirow{2}{*}{0.60} \\
\hline Positive (6) & $2(5.0 \%)$ & $4(10.0)$ & \\
\hline \multicolumn{4}{|l|}{ Ki67 } \\
\hline$\leq 30(27)$ & $14(29.2)$ & $13(27.1)$ & \multirow{2}{*}{0.03} \\
\hline$>30(21)$ & $3(6.2)$ & $18(37.5)$ & \\
\hline \multicolumn{4}{|l|}{ Her2/neu } \\
\hline Low/weak (27) & $10(20.8)$ & $17(35.4)$ & \multirow{2}{*}{0.517} \\
\hline Moderate/strong (21) & $7(14.6)$ & $14(29.2)$ & \\
\hline
\end{tabular}

Abbreviations: miR-34a, MicroRNAs-34a; TNM, TNM classification of malignant tumors; ER, estrogens receptor; PR, progesterone receptor; HER2, human epidermal growth factor receptor-2.

Data are presented as a number for all others. \%, percent of total samples. 
TWIST1, ZEB1 and ZEB2, and NOTCH1 expression levels. As shown in Figure 2A, the miR-34a expression in BT-549 cells transfected with miR-34a mimic was significantly increased. Upon overexpression, miR34a reduced NOTCH1, TWIST1, and ZEB1 levels,
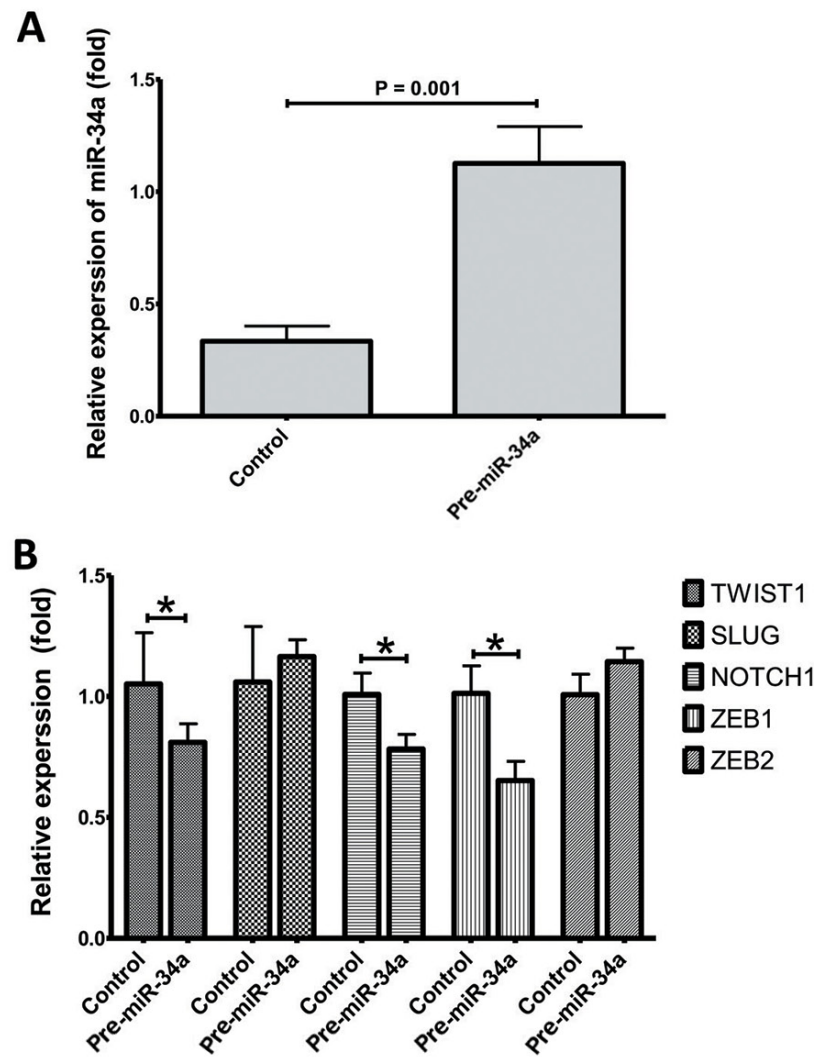

C

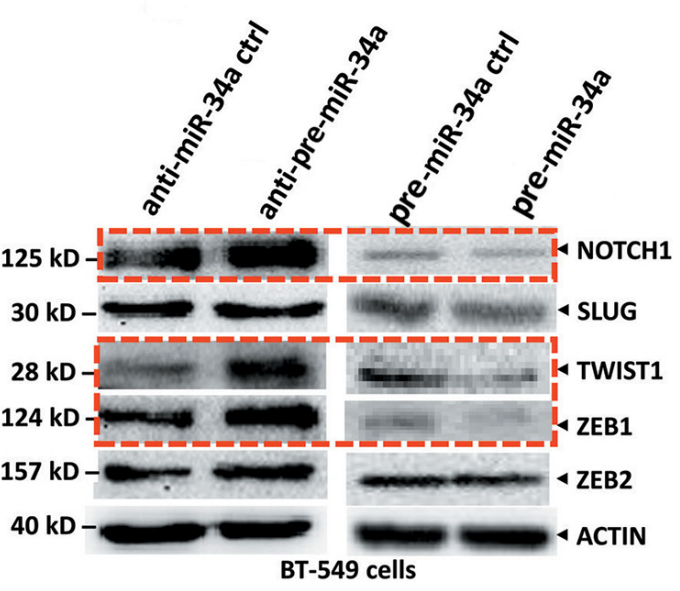

although it expressed a less significant reduction in their corresponding protein levels $(P>0.05$; Figures $2 \mathrm{~B}-2 \mathrm{C})$, indicating both transcriptional and post-transcriptional regulations. However, overexpression of miR-34a did not substantially affect SLUG, ZEB2 expression $(P \geq 0.05$;
D
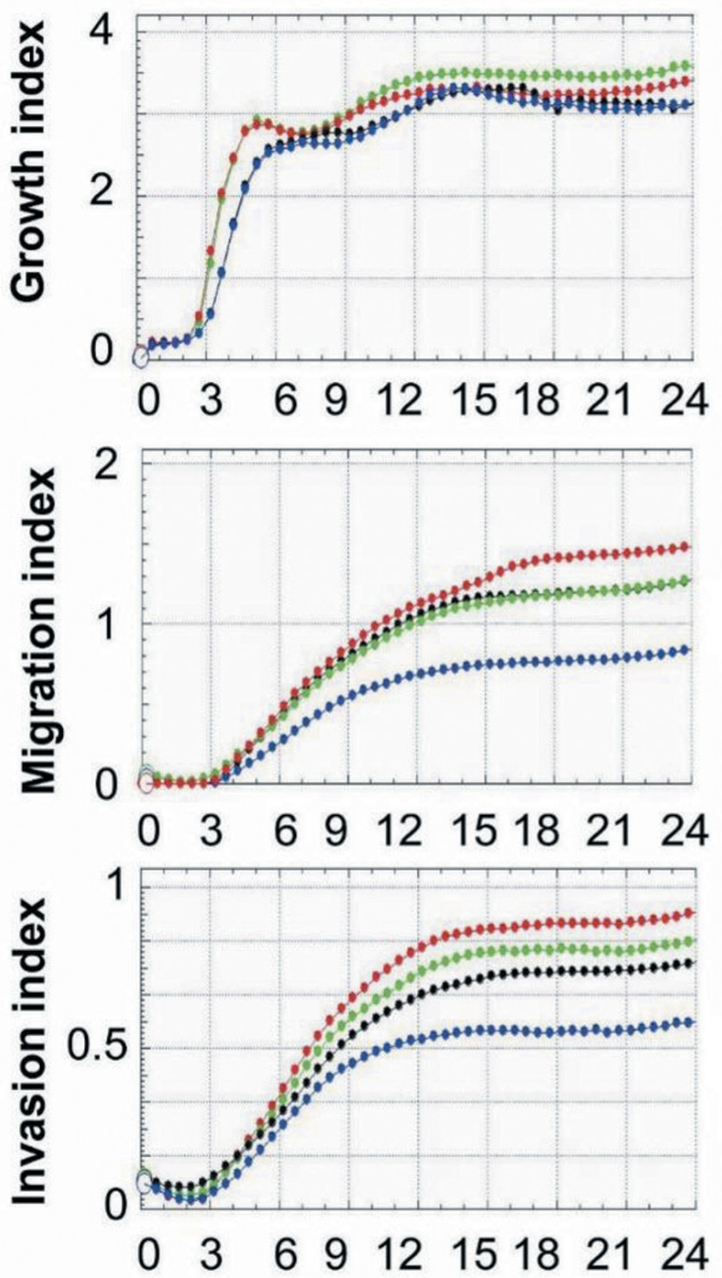

Time (hour) anti-miR-34a ctrl

anti-pre-miR-34a

pre-miR-34a ctrl

pre-miR-34a 
Figures 2B-2C) and SNAIL1 expression (data not shown). Consistently, after the inhibition of miR-34a, TWIST1, NOTCH1 and ZEB1 protein levels were significantly increased. (Figure 2C). All these results suggested that miR-34a is able to inactivate the EMT signaling pathway with mediation of NOTCH1, TWIST1 and ZEB1 in MBC cell lines.

\section{MicroRNA-34a inhibits migrations and invasion in $\mathrm{BC}$ cells in vitro}

To investigate miR-34a's effects on $\mathrm{BC}$ cell growth, migration, and invasion, pre-miR-34a for the overexpression of precursor miR-34a (pre-miR-34a), or anti-miR-34a for the overexpression or inhibition of miR$34 \mathrm{a}$, were transiently transfected into the MBC cell lines, BT-549 (Figure 2D) and MDA-MB-435 (Supplementary Figure 2), respectively. Our results clearly showed that miR-34a's expression did not significantly inhibit cell proliferation in BT-549 cells. Pre-miR-34a restoration inhibits cell migration and invasion in comparison to the pre-controls. Up-regulated miR-34a contributed to a significant down-regulation of cell migration and invasion. Strikingly, the inhibited-miR-34a in BT-549 BC cells showed more significant migrations and invasions after $12 \mathrm{~h}$ of cell culture. Here, we did not observe significant changes in cell migration in MDA-MB-435 cell lines with anti-miR-34a overexpression (Supplementary Figure 2); thus, we concluded that miR-34a functions are dependent on MBC cell line types. Therefore, miR-34a suppresses several malignancy parameters in human breast tumor cells, but has no obvious effects on cancer cell growth.

\section{Evaluation of EMT status and miR-34a in $\mathrm{BC}$ cell lines}

Although previous studies have demonstrated that EMT-TFs played a fundamental role in the initiation, aggregation, progression, and metastasis of $\mathrm{BC}$ by inducing the activation of NOTCH1, TP53, and TGF- $\beta$ cascade $[10,13,33]$, EMT-TFs' expression patterns, in comparison to miR-34a, have not been well characterized in human BC. To assess whether EMT-TFs and NOTCH1 are important mediators of metastatic potential in $\mathrm{BC}$ cells, we first evaluated NOTCH1, TWIST1, SLUG, and ZEB1/2 expression in a panel of established metastatic and non-metastatic BC cell lines (Figure 3). NOTCH1, SLUG, TWIST1, and ZEB1/2 expression levels, in contrast to miR-34a, were verified in BC cell lines, which confirmed that NOTCH1 and EMT-TFs partially inhibit miR-34a expression in cells (Figures 3A-3E). Altogether, these data suggested that NOTCH1 (Figure 3A), TWIST1 (Figure 3C), and ZEB1 (Figure 3D) are reverse correlated with miR-34a in the both $\mathrm{MBC}$ and $\mathrm{BC}$ cell lines (especially BT-549 and MDA-MB-435 cell lines) $(\mathrm{P} \leq 0.001)$. However, the relative expression of the SLUG and ZEB2
A

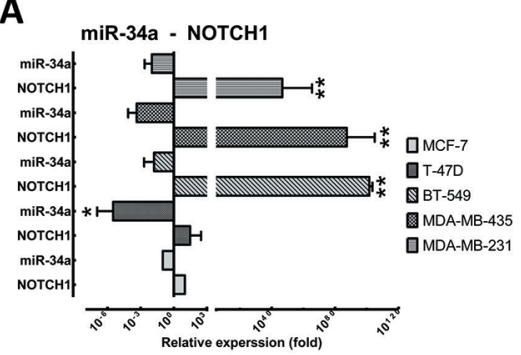

D

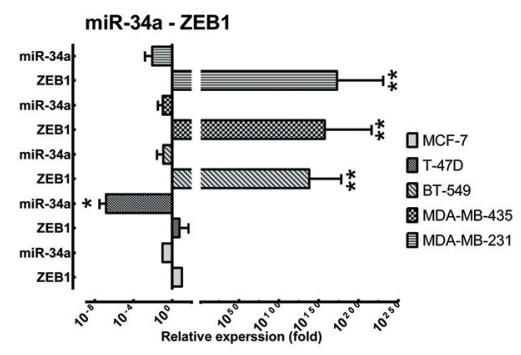

B

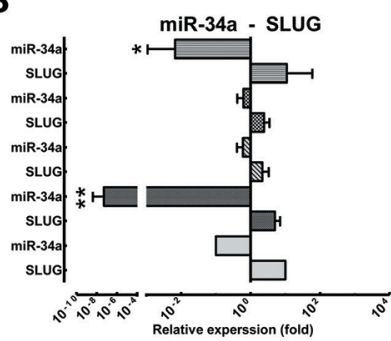

$\mathbf{E}$

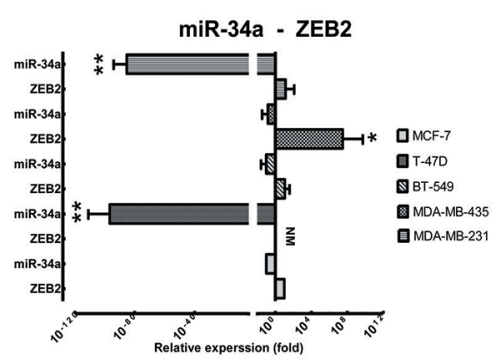

C

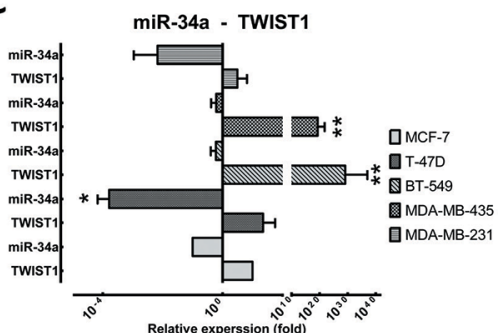

$\mathbf{F}$

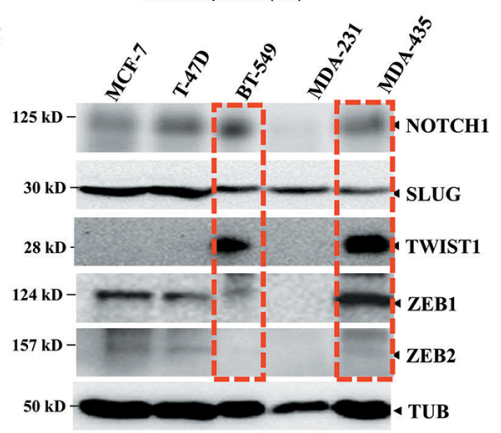

Figure 3: EMT-TFs demonstrate high expression levels in MBC cell lines in front of miR-34a expression. Relative expression levels of NOTCH1 A., SLUG B., TWIST1 C., and ZEB1 D. and ZEB2 E. were detected in non-metastatic BC cell lines (MCF7 and T47D), and MBC cell lines (MDA-MB-231, MDA-MB-435 and BT-549), in comparison to relative expression levels of miR-34a using qRT-PCR. F. EMT-TFs expression level was detected in MBC cell lines by western blot. Totally, EMT-TFs were overexpressed in invasive $\mathrm{BC}$ cell lines. Similar results were obtained from three independent experiments. Horizontal bars show with mean $\pm \mathrm{SD}$. The Tubulin (TUB) in western blot assay, and 18S or U6 in qRT-PCR as controls. ( $P<0.05$ and $* * P<0.001$ versus MCF-7 group). 
and $\mathrm{miR}-34 \mathrm{a}$ expression was not significantly co-related in $\mathrm{BC}$ cell lines (Figures 3B and 3E, respectively). In addition, the EMT-TFs protein expression was higher in both MBC cell lines, MDA-MB-435 and BT549 in comparison to non-metastatic BC cell lines (Figure 3F). In considering both gene and protein levels, TWIST1, SLUG, and ZEB1 expressions were higher compared to the lower expression of miR-34a. These results suggested that the expression of EMT-TFs positively correlates with the metastatic potential of $\mathrm{BC}$ cell lines.

\section{EMT-TFs overexpression in malignant progression of $\mathrm{BC}$ tumors}

To emphasize the role of EMT-TFs in promoting tumor metastasis, the expressions for NOTCH1, SLUG, TWIST1, and ZEB1/2 were examined by qRT-PCR from $\mathrm{BC}$ and their normal adjacent tissues. As the Figure 4 showed, the expressions of NOTCH1, SLUG, and ZEB1/2 were significantly increased in tissue samples compared to the matched-control group (Figure 4A). These results demonstrated a significant increase of EMTTFs in cancer tissues. For each case of 33 patients, an index of all EMT-TFs and NOTCH1 expression of the MBC tissue (qRT-PCR score) was subtracted by that of normal tissue, and the resultant values (malignant-NAT) from all 33 cases were presented in Figure 4B. Of the 33 cases examined, 19 (57.58\%) showed significantly higher expression of EMT-TFs in the cancerous tissues in comparison to the corresponding adjacent normal tissues; while another 7 (21.21\%) showed similar levels of expression in both tissues; only 7 (21.21\%) displayed a reverse expression pattern, in which EMT-TFs expression was lower in the cancer tissues than that of normal groups. So, EMT-TFs are differentially expressed in malignant BC tissue compared to the normal tissue.

We then analyzed the association between survival time and NOTCH1, TWIST1, SLUG, and ZEB1/2 with an online tool [34] to further extend the clinicopathologically-relevant context, with the exclusion of systemic treatment, endocrine therapy, and chemotherapy. The results revealed that higher ZEB1 expression was considerably associated with a worse overall survival (OS, $H R=0.55, P=0.0083$ ), worse relapse free survival (RFS, $H R=0.64, P=0.001$ ), post progression survival (PPS, $H R=0.64, P=0.062$ ), and distant metastasis free survival (DMFS, $H R=0.6$, $P=0.0003$ ) of BC patients (Figure 4C). There was no significant difference between SLUG, NOTCH1, ZEB2, and TWIST1 in BC patients (Table 2). These data indicated that $\mathrm{ZEB} 1$ could be used as the most important potential predictor of survival in the BC patients.

In considering both tumor and normal samples, miR34 a was inversely correlated with NOTCH1 $(r=-0.563, P$ $=0.001$; Figure 5A), SLUG $(r=-0.374, P=0.009$; Figure 5B), ZEB1 $(r=-0.505, P=0.001$; Figure 5C), and ZEB2
( $r=-0.317, P=0.028$; Figure 5D) expressions. We found that TWIST1 ratios were not significantly correlated with the frequencies of miR-34a expression $(r=-0.093, P=$ 0.532; data not shown). Therefore, we proposed that EMTTFs over-expression might suppress miR-34a expression of $\mathrm{BC}$.

\section{MicroRNA-34A inhibits BC progression by targeting TWIST1, NOTCH1, and ZEB1}

We next explored whether miR-34a is able to directly target NOTCH1, TWIST1 and ZEB1 gene expression at the post-transcriptional level by regulating the activity of mRNA (Figure 6). First, prediction online databases, like miR base databases, identified that NOTCH1, TWIST1 and ZEB1 were potential downstream targets of miR-34a through their interactions in the 3'-UTR region (Figure 6A). Thus, luciferase reporter assays carried out by co-transfection of different amount of pre-miR-34a $(0,10,30$, and $90 \mathrm{ng}$ each well) along with NOTCH1, TWIST1 and ZEB1 wild-type 3'-UTR reporter genes respectively in BT-549 cells contributed to significant reductions in luciferase activity (Figures 6B-6D). Luciferase activities are significantly reduced in a dose dependent manner in all NOTCH1, TWIST1 and ZEB1 reporter genes. However, co-transfection of miR34a, along with the NOTCH1, TWIST1, and ZEB1-mut 3'-UTR or control reporter genes, did not show significant effects on the luciferase activity. These results suggested that miR-34a directly targets multiple genes of NOTCH1, TWIST1, and ZEB1 in vitro.

\section{Co-delivery of miR-34A and Thymoquinone inhibits BC metastasis by regulating EMT-TFs}

Our previous investigation reported that Thymoquinone (TQ), small molecular component of Nigella sativa, could be used as an inhibitor of cancer growth and metastasis [35]. The epigenetic modulation of the EMT promoter is associated with TWIST1 and cadherins down-regulation and metastasis by TQ treatment in $\mathrm{BC}$ cells [35]. With this background, we investigated the synergistic effects of TQ and miR-34a on the expression of EMT-associated proteins. Cancer cells were treated with TQ, pre-miRNAs vector, or both. Both proteins and gene analysis showed that $\mathrm{TQ}+\mathrm{miR}-34 \mathrm{a}$ significantly inhibited the mRNA level expression of NOTCH1 $(P=0.073$; Figure 7A) TWIST1 ( $P=0.062$; Figure 7B) and ZEB1 $(P=0.005$; Figure 7C) in the BT-549 cell line. However, no significant changes in NOTCH1 and ZEB1 expression were observed in the TQ treated groups (Figures 7A and $7 \mathrm{C}$, respectively). Interestingly, the protein levels of ZEB2 and SLUG were expressed minimally or completely unexpressed in three groups in comparison to the control. In addition, some extent of reduction in ZEB2 was also observed, by TQ through either treatment or miR-34a 
A

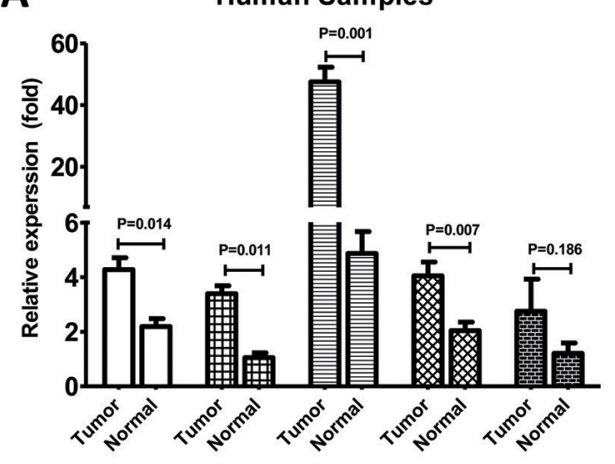

C
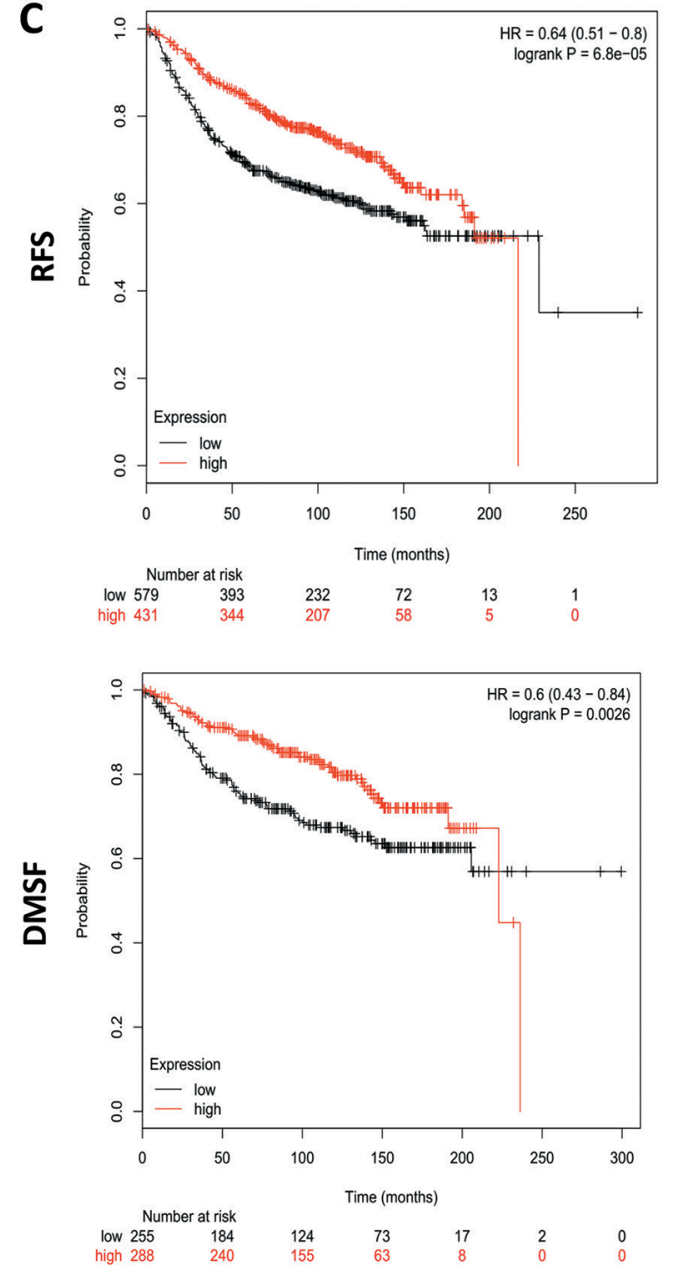

B
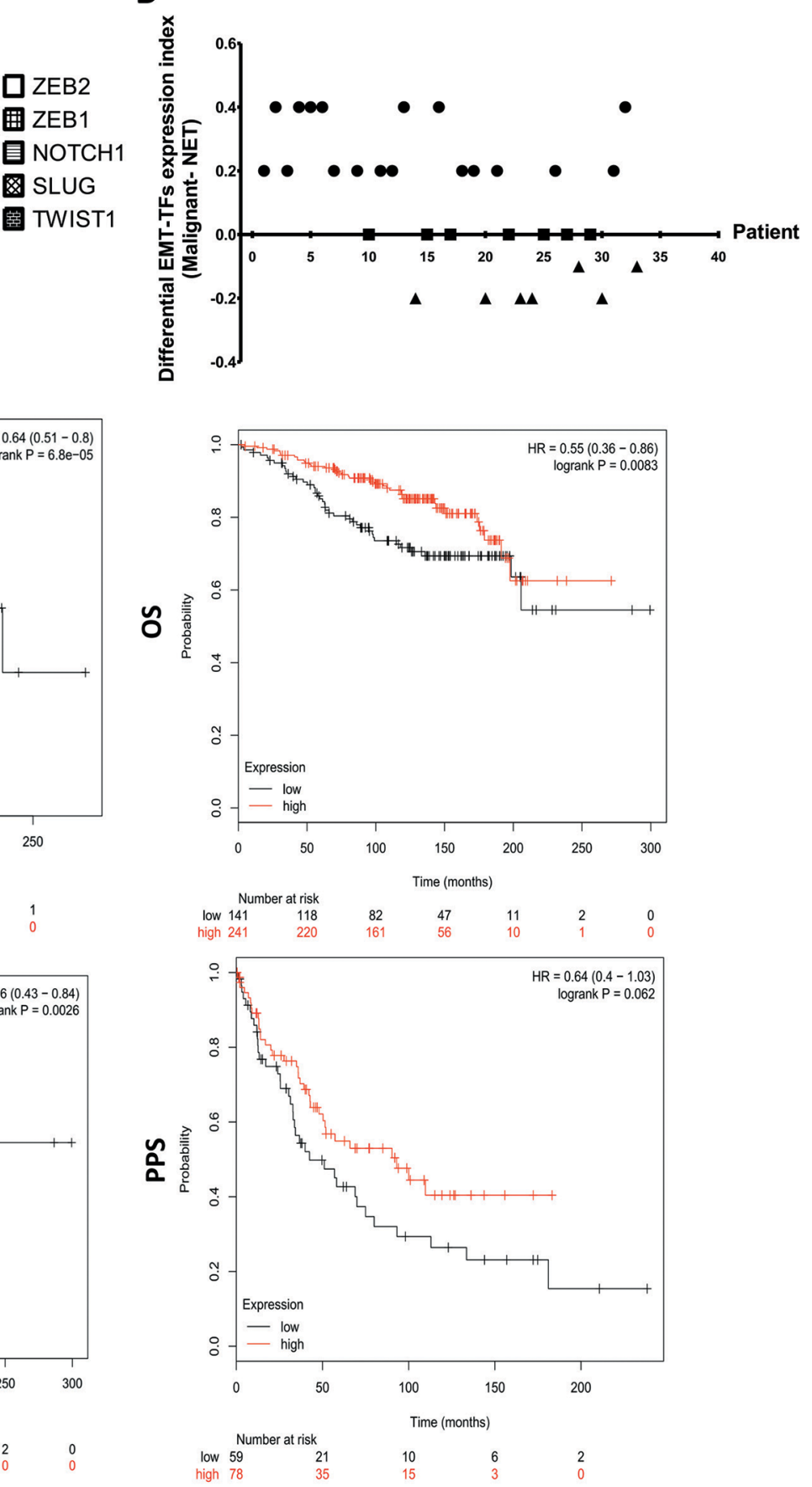

Figure 4: EMT-TFs are frequently upregulated in BC tissues. A. SLUG, TWIST1 ZEB1/2 and NOTCH1 expression level were detected in MBC tissues and matched with the corresponding paired adjacent normal tissue through qRT-PCR. B. EMT-TFs are differentially expressed in primary malignant $\mathrm{BC}$ tissue compared with the corresponding paired adjacent normal tissue. For each case of the 33 patients, index of all EMT-TFs (SLUG, TWIST1, and ZEB1/2) and NOTCH1, expression (qRT-PCR score) of the primary tissue was subtracted by that of the corresponding paired adjacent normal tissue, and the resultant values (Malignant-NAT) from all 33 cases were used for plotting. The relative of EMT-TFs expression level between primary cancer and paired adjacent tissue of each case were represented as a dot. EMT-TFs are considered to be significantly upregulated, similar or negative in primary tissue when compared with the corresponding paired adjacent tissue only if the calculated index is $>0$ (circular dots), 0 (square dot), $<0$ (triangular dots), respectively. C. Kaplan-Meier survival analysis for the relationship between survival time and ZEB1 signature in BC was performed by using the online tool (http://kmplot.com/analysis/). All data were showed with mean \pm SD. Data presented is a representative of three different experiments. The qRT-PCR results were normalized to18S. RFS, relapse free survival; OS, overall survival; DMFS, distant metastasis free survival; PPS, post progression survival. 
Table 2: Kaplan-Meier survival analysis for the relationship between survival time and NOTCH1, TWIST1, SLUG, and ZEB2 signature in breast cancer

\begin{tabular}{lcccc}
\hline EMT-TFs & RFS & OS & DMSF & PPS \\
\hline TWIST1 & 0.16 & 0.19 & 0.043 & 0.3 \\
SLUG & 0.14 & 0.18 & 0.34 & 0.26 \\
ZEB2 & $\mathbf{0 . 0 5}$ & 0.092 & $\mathbf{0 . 0 3 9}$ & 0.11 \\
NOTCH1 & $\mathbf{0 . 0 9 6}$ & 0.14 & 0.32 & 0.18 \\
\hline
\end{tabular}

Abbreviations: EMT-TFs, EMT-inducing transcription factors; ZEB1\&2, Homo sapiens zinc finger E-box binding homeobox 1 and 2; NOTCH1, Notch homolog 1, translocation-associated; SLUG, Zinc finger protein; PPS, post progression survival; LSD, least significant difference; RFS, relapse free survival; OS, overall survival; DMFS, distant metastasis free survival.
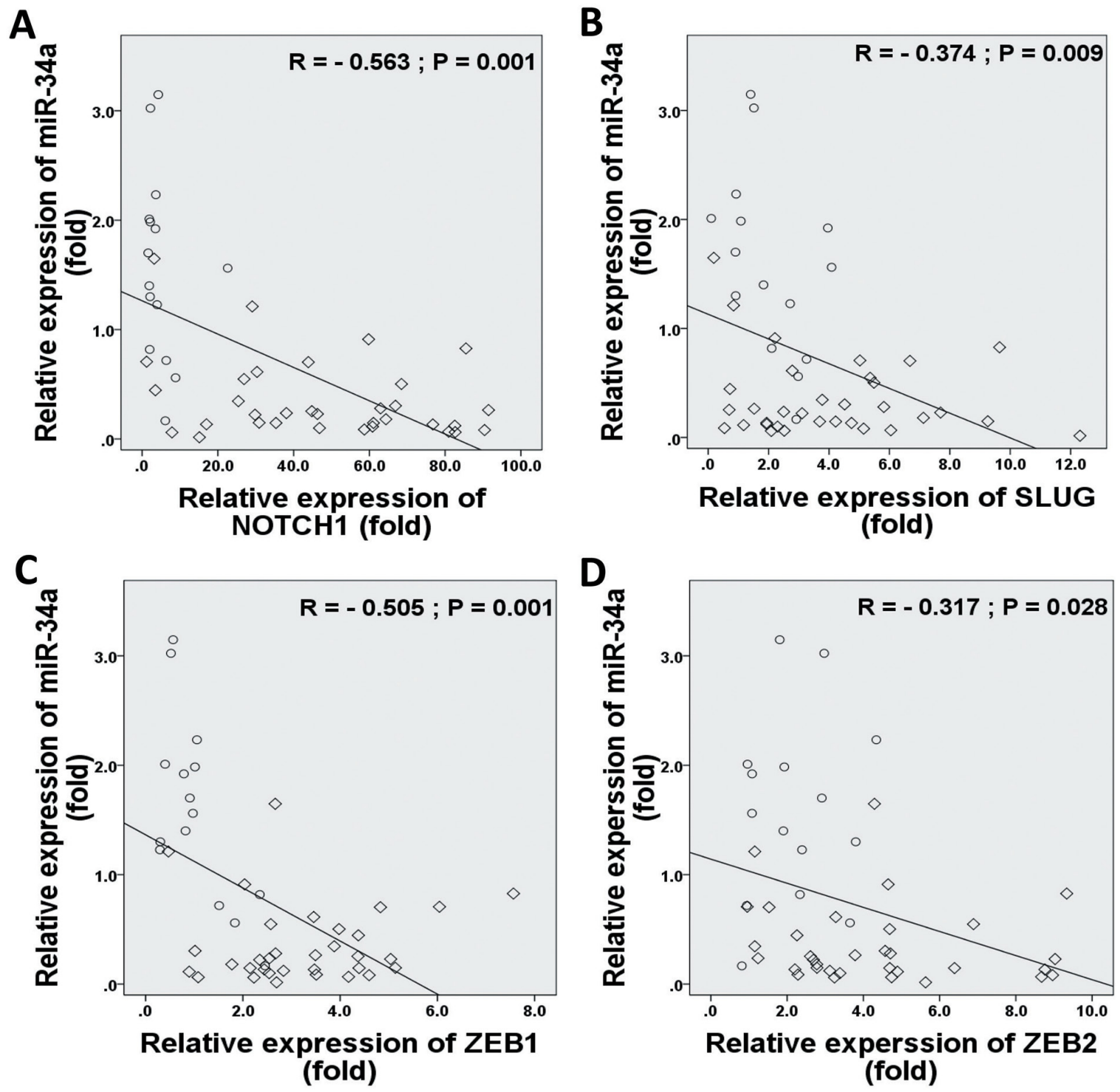

Figure 5: Correlations between relative expression levels of NOTCH1 A., SLUG B., ZEB1 C., and ZEB2 D. with miR-34a expression level. Data indicate significantly negative associations in EMT-TFs and miR-34a expressions in MBC patients. The diamond indicates human BC specimens $(n=33)$, and circles represent paired adjacent normal tissue $(n=15)$. Data were analyzed by Spearman's rank correlation coefficient. 
overexpression (Supplementary Figure 3). Thus, the obtained data proposes that co-delivery of TQ and miR34 a could produce synergistic effects on tumor growth and migrations.

\section{DISCUSSION}

The experimental investigation of this study identified a novel regulatory mechanism of EMT-TFs using miR-34a. Our results indicated that miR-34a inhibits TWIST1, ZEB1, and NOTCH1 expression upon their 3'-UTR activity in BC cells and reduces the metastatic and invasive features of MBC effectively. We also revealed that miR-34a expression is down-regulated in $\mathrm{MBC}$ tissues compared to normal tissues. Moreover, we found a significant inverse correlation between miR34a expression and EMT-TFs expression. The forced miR-34a expression in MBC cell line BT-549 powerfully inhibits cell migrations and invasion. Importantly, miR34 a does not have any inhibitory effects on SLUG and ZEB2 in BC cells we investigated. We therefore presented the first comprehensive report of epigenetic inactivation of the EMT-TFs/miR-34a pathway in human BC that can potentially alter the stability of these regulations in EMT
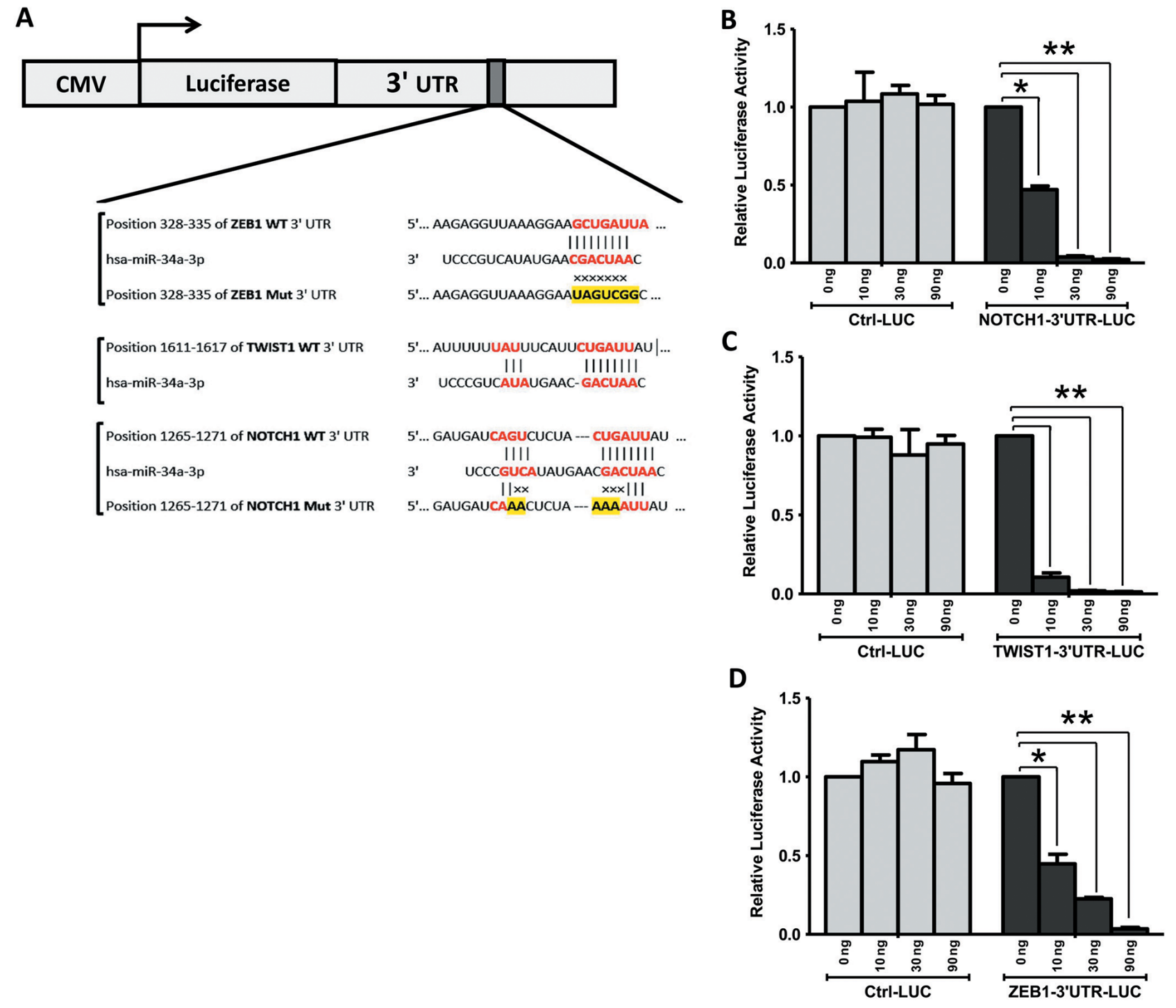

Figure 6: TWIST1, NOTCH1 and ZEB1 are direct targets of miR-34a. A. miR-34a binding sequences at the 3'-UTR of NOTCH1, TWIST1 and ZEB1. Mutation was generated in the NOTCH1, and ZEB1 3'UTR sequence in the complementary site for the seed region of miR-34a. BT-549 cells were transfected with either the wild-type or mutant NOTCH1 B., TWIST1 C., ZEB1 D. -3'UTR luciferase reporter genes, together with different concentrations of miR-34a mimic or controls $(0,10,30$, and $90 \mathrm{ng})$. The relative luciferase values were measured and normalized by luciferase reporter assay after 48 h. NOTCH1, TWIST1, and ZEB1 expression were directly down-regulated by miR-34a. All data were showed with mean \pm SD. Similar results were obtained from three independent experiments. (* $P<0.05$ and $* * P<0.001$ versus 0 ng treated group). 
and mesenchymal state, consequently contributing to metastasis.

The underlying mechanisms governing $\mathrm{MBC}$ remained largely undefined, with few studies proposing the inhibitions of EMT-TFs/miR-34a feedback loop as a model for the dissemination process. Several signaling pathways, such as NOTCH1, TGF- $\beta$-SMAD, and Wnt/ $\beta$ catenin, initiate the reprogramming of gene expression and transcriptional changes during EMT [10, 13, 33]. These signaling pathways, along with activating secondary pathways, like PI3K-AKT, RAS/MAPK, p38 MAPK and JUN N-terminal kinase, regulate the pathogenesis and progression of tumor as they control cell proliferation, migrations, differentiation, apoptosis, and angiogenesis [36, 37] (Figure 8). Dysregulation of these signaling pathways and aberrant activations of target genes in the EMT-inducing signaling pathways contribute to MBC progression [38, 39]. The inactivation of EMT-TFs by the human tumor suppressor micro-RNAs is a new epigenetic-targeted therapy for MBC. Consequently, several miRNAs, including miR-1 [40], miR-34a [30, 41, 42], miR-100 [43], miR-125b [44], and miR-142 [45] have been proposed to inhibit or reduce the EMT process during the advanced stage of $\mathrm{BC}$ [46]. A number of studies have suggested that miR-34a is potentially a regulatory microRNA that is usually up-regulated in breast, pancreatic, renal and gastric cancer [47-50]. Nevertheless, these reports on the interaction between miR-34a expression and the inactivation of EMT signaling pathway are still limited [46].

Information about regulators and mediators of EMT-TFs/miR-34a loops is still murky and unknown. Our study seeks to address that miR-34a expression is lower in human BC tissues than in normal breast tissues. Studies indicated that frequencies of $\mathrm{miR}-34 \mathrm{a}$ expression in the $\mathrm{BC}$ are controversial [51-53]. The downregulation of miR-34a expression in breast could be associated with the frequent deletion of chromosome 1p36, TP53 mutations and $\mathrm{CpG}$ methylation of the miR-34a promoter in these tumors [52, 54]. MiR-34a was inactivated by aberrant $\mathrm{CpG}$ methylation in multiple types of cancer; but breast tumors were not investigated yet [52]. A number of studies have concluded that knockdown of some EMT-TFs in cancer cell lines interacting with miR-34a inhibits cancer progression and metastasis $[19,33,55,56]$. Now, the details of how miR-34a physically interacts with EMT-TFs and how this interaction inhibits $\mathrm{MBC}$ remain unclear. It is possible that miR-34a may interact with 3'-UTR of EMTTFs by stem-loop structure and change the conformation of the binding and landing site of other EMT-activation proteins, possibly inhibiting the protein expression of EMT and disrupting the post transcriptional modification pattern through methylations and ubiquitin-proteasome pathway [57]. This hypothesis needs further investigation based on epigenetic and structural analyses. Despite this, it appears that the reduction of EMT-features and their modifications through the interaction between miR-34a and EMT-TFs may be a major functional mechanism of miR-34a in our present study.

To our knowledge, the correlation between downregulation of miR-34a expression and EMT-TFs regulations in $\mathrm{BC}$ was investigated systematically in this study for the first time. Despite some limitations in sample size, the current data showed an inverse
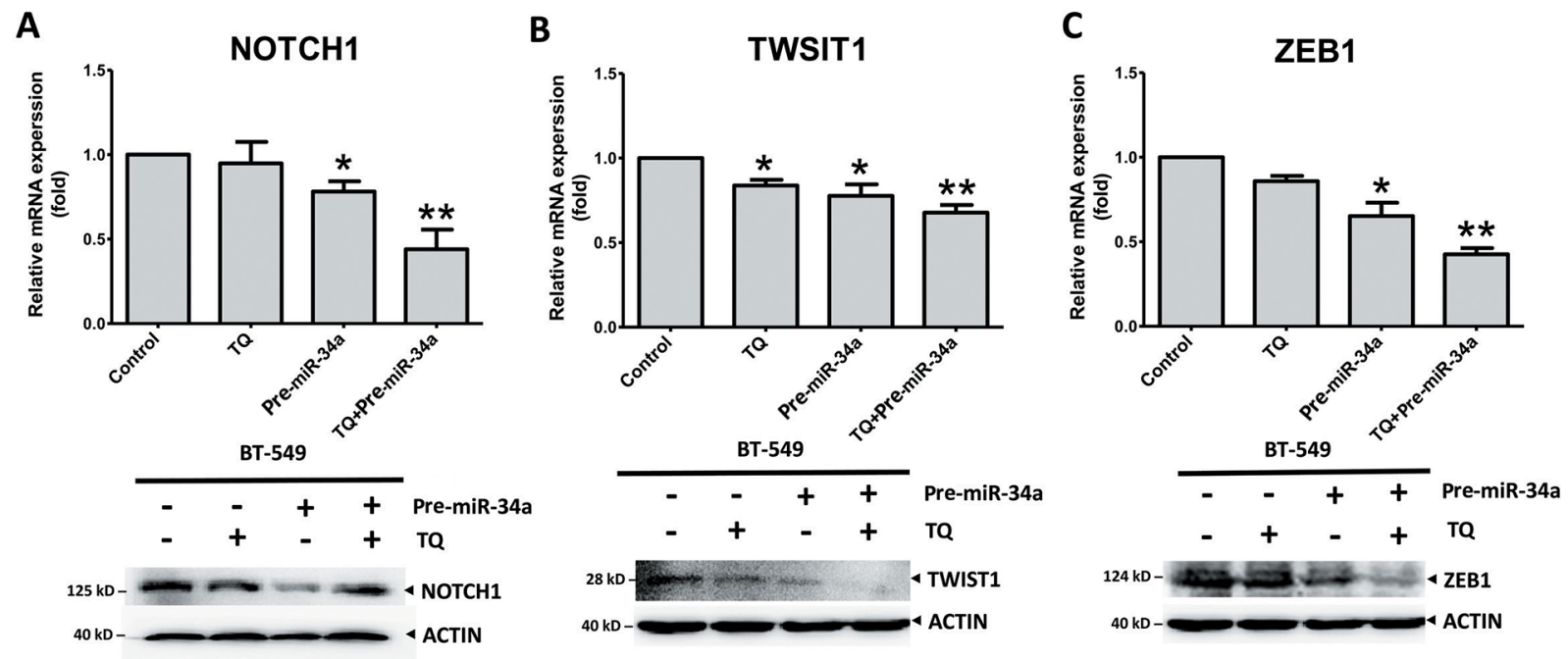

Figure 7: Synergic effects of thymoquinone (TQ) and miR-34a on mRNA (top panel) and protein (bottom panel) level expression of EMT-TFs. TQ $(5 \mu \mathrm{M})$ treatment for $6 \mathrm{~h}$ for RT-PCR or $12 \mathrm{~h}$ for Western blot pre-miRNAs $(20 \mathrm{ng}$ of each) treatment for $36 \mathrm{~h}$ inhibited the expression of NOTCH1 A., TWIST1 B., and ZEB1 C. in the BT-549 cell line. Results expressed as mean \pm SD, and independently repeated with three times. qRT-PCR results normalized to $18 \mathrm{~S}$ or U6 and compared with the untreated cells as a control. In western blot $\beta$-actin (ACTIN) as an internal control (* $P<0.05$ and ** $P<0.001$ versus control group). 
correlation between miR-34a expression and EMT-TFs expression in MBC tissues, indicating that miR-34a could be a promising and novel noninvasive biomarker in $\mathrm{BC}$ diagnosing. There is some evidence supporting this finding, showing the negative correlations of miR$34 \mathrm{a}$ with the biomarkers of most cancers. Survival time and clinicpathological analysis results showed that the strongest association of ZEB1 expression is correlated with EMT and BC metastasis, raising the question on how ZEB1 and NOTCH1 induces EMT signaling activation and whether ZEB1's increased expression in BC cells is linked to an altered or disturbed EMT process.

Previous studies indicated that miR-34a significantly suppressed proliferation, invasion, and metastasis of $\mathrm{BC}$ cells, which correlated to the overexpression of some EMT-TFs [19, 58, 59]. Some of these results are inconsistent with our findings, or not studied in BC. Ahn et al. (2012) demonstrated that ZEB1 targeted miR-34a as a direct tragedian of miR-34a in human lung cancer
[60]. However, all these findings indicated that miR-34a might have a significant impact on the tumorigenesis of human cancer by targeting differential EMT signaling pathways other than those in BC. It is likely the initiation binding feedback loop of EMT-TFs /miR-34a is different depending on the types of cancer cell and physiological features. All of this insufficient information could contribute to additional inconsistencies and potential selection bias. Thus, our data need to be substantiated by an appropriate prospective and comprehensive basic study.

Interestingly, this is the first report demonstrating that the co-delivery of miR-34a and TQ is able to inactivate the downstream of the EMT signaling pathway by directly targeting TWIST1 and ZEB1 in vivo. Thus, co-delivery of TQ and miR-34a could produce synergistic effects on tumor growth and migrations, and a nanosystem-based co-delivery of tumor suppressive miRNAs and natural compound TQ may be a promising combination for therapeutic strategy against $\mathrm{MBC}$ by

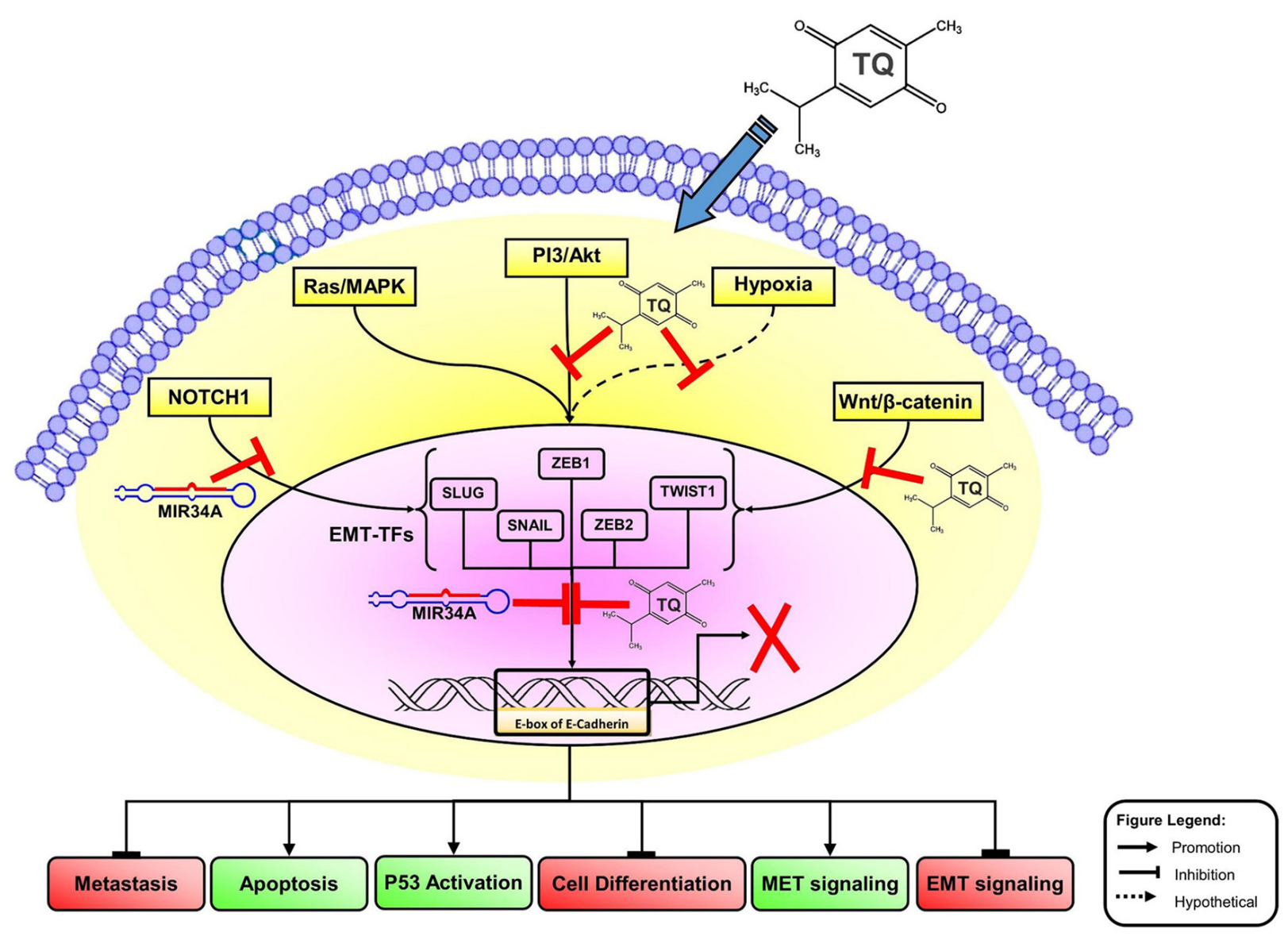

Figure 8: Molecular model of BC metastasis suppressed via TQ/miR-34a-initiated signaling pathways. This schematic carton shows the major triggering of EMT-inducing signaling pathways, like Wnt proteins (NOTCH), Ras/MAPK kinas, PI3-kinase/ Akt and hypoxia (ROS). Co-delivery of TQ/miR-34a leads to repression of metastatic, cell differentiation, and EMT factures in front of inducing of apoptosis and TP53 activations and MET features of BC cell. For more details see manuscript text. TQ, Thymoquinone; miR34a, microRNAs-34a; PI3K/AKT, phosphatidylinositol 3-kinase (PI3K)/Akt; ROS, reactive oxygen species; MAPK, Mitogen-Activated Protein Kinase; ZEB, zinc-finger E-box-binding; EMT, epithelial to mesenchymal transitions, MET, mesenchymal to epithelial transitions; EMT-TFs, EMT-inducing transcription factors. 
down-regulating TWIST1, NOTCH1 and ZEB1 in the near future. Previous studies proposed that TQ induces cell cycle arrest and triggers apoptosis of tumor cells through p38, NF- $\mathrm{kB}$ and ERK signaling pathways [11, 35, 61-64]. It has been reported that the anti-metastatic effects of TQ are likely to be mediated by the stimulation of miRNA profiles [35, 65-68]. Targeting miRNA and TQ may deliver a new outlook of tumor metastasis suppression by targeting EMT-TFs pathways in different cancer cells [35, 69-71]. It is not yet known whether miRNA's TQ-targeting mechanism and its specifics in controlling EMT could be associated with this activity $[65,66,71]$. In our current study, we found that EMT-TFs/TQ/miR-34a axis plays critical roles in regulating MBC contribution. Based on these results, we created a molecular model demonstrating the synergistic effect of miR-34a and TQ in MBC cell line (Figure 8). Figure 8 shows the transcriptional regulators of EMT and a representation of some points of intersection at $\mathrm{TQ} / \mathrm{miR}$-34a-inducing signaling pathways. These results clearly show that TQ/miR-34a is a potential therapeutic agent for further development in the management of $\mathrm{BC} /$ MBC. The aforementioned outcomes might help describe a possible aim on why EMT-TFs/TQ/miR-34a contributes to $\mathrm{MBC}$ progression, helping in the identification of a novel therapeutic target of MBC progression.

In conclusion, we indicate that the lower level of expression of miR-34a could be a promising and novel biomarker for MBC. The epigenetic inactivation of the EMT-TFs/miR-34a pathway can potentially push the equilibrium of these regulations toward EMT, thereby contributing to metastasis. MiR-34a alone could serve as a potential therapeutic agent for $\mathrm{MBC}$ and, combined with $\mathrm{TQ}$, they might synergistically enhance the therapeutic effects significantly.

\section{MATERIALS AND METHODS}

\section{Cell culture and transfections}

Two non-metastatic $\mathrm{BC}$ cell lines, $\mathrm{MCF}-7$ and T-47D, and three MBC cell lines, BT-549, MDAMB-231, and MDA-MB-435, were purchased from American Type Culture Collection (ATCC, Manassas, VA, USA). All these cell lines were cultured in RPMI-1640 or DMEM supplemented with $10 \%$ fetal bovine serum (Thermo Fisher Scientific, Waltham, MA, USA) and 1\% penicillin-streptomycin (Sigma-Aldrich, St Louis, MO, USA) [72]. Cell cultures were incubated at $37{ }^{\circ} \mathrm{C}$ with $5 \% \mathrm{CO}_{2}$ in a humidified incubator. In this study, TQ was purchased from Sigma-Aldrich (St. Louis, MO, USA) and suspended in dimethyl sulfoxide (DMSO). In addition, different concentrations of TQ were used to treat cancer cell lines, while DMSO was used as control. The plasmids for miR-34a of miRNA inhibitors (HmiR-AN0440-SN-5), precursor miRNA clone in non-viral vectors (HmiR0005MR04) and respective negative controls (CmiR-AN0001-
SN, CmiR0005-MR04) (GeneCopoeia, Inc, USA) were transfected into $1 \times 10^{5}$ cells per well in 24 well plates (Qiagen, Hilden, Germany).

\section{Plasmids}

The wild type DNA fragment containing part of the wild type DNA fragment of the 3'-UTR region $(-1611$ to +1617 from the transcriptional initiation site) of the TWIST1 gene (NM_000474.3), miRNA 3' UTR TWIST1 target clone in luciferase reporter vector (Cat\# HmiT018328-MT01) and its miRNA Target clone control vector (Cat\# CmiT000001-MT01) were purchased from GeneCopoeia Co. (GeneCopoeia Inc., MA, USA). The plasmids for miR-34a of miRNA inhibitors (HmiRAN0440-SN-5), precursor miRNA clone in non-viral vectors (HmiR0005-MR04) and respective negative controls (CmiR-AN0001-SN, CmiR0005-MR04) were purchased from GeneCopoeia, Inc, USA. The wild type DNA fragment containing part of the 3'-UTR region $(-328$ to +335 from the transcriptional initiation site) of the ZEB1 gene (NM_001174096) were amplified from human genomic DNA, and inserted into the pGL3-basic (Promega, Madison, WI, USA), an empty pGL3 vector used as a control. The mutant DNA sequences of the $Z E B 1,3$ '-UTR region was synthesized and inserted into pGL3-basic vector. The pGL3-hNOTCH1-Luc reporter plasmid was kind gifts from Prof. Benjamin Purow (University of Virginia, Charlottesville, VA, USA) [73].

\section{Tissue samples and clinical data}

The study was approved by the Ethics Committee of the Southwest Medical University according to the Helsinki Declaration (1983 Revision) [74, 75, 76]. In total, 48 fresh or formalin-fixed, paraffin-embedded MBC cases surgical biopsy specimens were obtained from affiliated Hospital of Southwest Medical University. All cases were diagnosed and confirmed by two oncologists and pathologist according to the World Health Organization (WHO) guidelines and the pTNM Union for International Cancer Control (UICC) pathological staging criteria. All patients signed consent and completed the questionnaire. The demographic and histopathologic variables of the all subjects such as medical, reproductive, family history, body mass index, tumor size, node status, disease stage, treatment and survival was obtained correctly according the interviewer-administered questionnaire. Based on the inclusion/exclusion criteria, the matched tumor tissues and non-tumor tissues samples comprised of 33 breast tumors, as well as normal breast tissues $(n=15)$ from epileptic resections. The tissues were immediately frozen in liquid nitrogen and stored at $-80{ }^{\circ} \mathrm{C}$ until future RNA and protein extraction [74]. Most demographic and clinical characteristics of the subjects were compared and shown in Supplementary Table 1. 


\section{Quantitative real-time PCR}

To quantify the expression of mRNA, qRT-PCR was performed according to standard protocols as previously described [35, 77]. Testing for hsa-miR-34a (Cat\# 4427975) was purchased from ABI. 18S or U6 snRNA from ABI (Cat\# 4427975) was set as internal control. Primers were listed in Supplementary Table 2.

\section{Western blot}

Total cell lysate of BC cell lines and frozen biopsies of human breast tissues were corrected by ice-cold RIPA lysis buffer (Roche, Diagnostics, Mannheim, Germany). A quantity of approximately $30 \mu \mathrm{g}$ of whole cell lysates per lane were separated using SDS polyacrylamide gels electrophoresis (SDS-PAGE) and transferred on to Immobilon PVDF membranes (Millipore, Corporation, Billerica, MA, USA) and probed with antibodies listed in the Supplementary Table 3.

\section{Cell growth, migration and invasion assay}

The real time analysis of cell migration, growth index and invasion were performed by using a real time cell analyzer (xCELLigence RTCA DP, Roche, Germany), as previously described in detail $[35,77]$.

\section{Luciferase reporter assay}

The assays were performed according to standard protocols as previously described $[35,76]$. In brief, assays were carried out by transfection of $10 \mathrm{ng}$ of each reporter constructs in BT-549 cells that were with $0,10,30$, and 90 ng miR-34a precursors respectively (Thermo Fisher Scientific) in 24-well plates. Dual-luciferase activity, expressed as relative light units (RLU), was measured using a luciferase kit (Promega, Madison, WI, USA).

\section{Bioinformatics}

Prediction potential targets of hsa-miR-34a in the 3'UTR of EMT-TFs was found by using the bioinformatics analysis based on the target prediction tools TargetScan (http://www.targetscan.org; release 5.1), PicTar (http:// pictar.mdc-berlin.de) and miRanda (http://www.microrna. org) and miRWalk (http://www.ma.uni-heidelberg). The online Kaplan-Meier data set tool was used to analyze the association between survival time and EMT-TFs (http:// www.kmplot.com/analysis/) [34].

\section{Statistics analysis}

All statistical analyses were performed using SPSS software version 21.0 (SPSS Inc., Chicago, IL, USA) with unpaired Student's t-test or otherwise stated. All graphs were produced by GraphPad Prism 5.0 for windows software (GraphPad Software Inc., La Jolla, CA, USA).

\section{Abbreviations}

MBC, metastatic breast cancer; BC, breast cancer; EMT, epithelial to mesenchymal transition; ZEB, zinc-finger E-box-binding; bHLH, basic helixloo-helix; SLUG, zinc finger protein SNAI2; EMT-TFs, EMT-inducing transcription factors; TWIST1, Twistrelated protein 1; miR-34a, MicroRNAs-34a; TGF- $\beta$, transforming growth factor beta; WHO, World Health Organization; UICC, Union for International Cancer Control; RLU, relative light unit; RFS, relapse free survival; OS, overall survival; DMFS, distant metastasis free survival; TQ, Thymoquinone; PPS, post progression survival; SD, standard deviation; UTR, untranslated region; LSD, least significant difference; qRT-PCR, quantitative reverse transcriptase-PCR;ROS, reactive oxygen species.

\section{ACKNOWLEDGMENTS}

The authors thank people who provided technical assistant in Key Laboratory of Epigenetics and Oncology, the Research Center for Precision Medicine, Southwest Medical University. We are great thankful for critical reading of the manuscript by Dr. Marzieh Dehghan Shasaltaneh.

\section{CONFLICTS OF INTEREST}

The authors declare that there is no conflicts of interest that perceived as prejudicing the impartiality of the research reported.

\section{FUNDING}

This work was supported by the National Natural Science Foundation of China $(81672887,81172049)$, Science and Technology Innovation Team of Colleges and Universities of Sichuan Province (13TD0032), the Research Foundation of the Science and Technology Department of Sichuan Province (14JC0797, 2015JY0038), and Southwest Medical University Grants for Postdoctoral Research (2016-BSH0001).

\section{REFERENCES}

1. Siegel R, Ma J, Zou Z, Jemal A. Cancer statistics, 2014. CA Cancer J Clin. 2014; 64: 9-29. doi: 10.3322/caac.21208.

2. Tao Z, Shi A, Lu C, Song T, Zhang Z, Zhao J. Breast Cancer: Epidemiology and Etiology. Cell Biochem Biophys. 2015; 72: 333-8. doi: 10.1007/s12013-014-0459-6. 
3. McGuire S. World Cancer Report 2014. Geneva, Switzerland: World Health Organization, International Agency for Research on Cancer, WHO Press, 2015. Adv Nutr. 2016; 7: 418-9. doi: 10.3945/an.116.012211.

4. Umemura S, Sakamoto G, Sasano H, Tsuda H, Akiyama F, Kurosumi M, Tokuda Y, Watanabe T, Toi M, Hasegawa T, Osamura RY. Evaluation of HER2 status: for the treatment of metastatic breast cancers by humanized antiHER2 Monoclonal antibody (trastuzumab) (Pathological committee for optimal use of trastuzumab). Breast Cancer. 2001; 8: 316-20.

5. Hurvitz SA, Lalla D, Crosby RD, Mathias SD. Use of the metastatic breast cancer progression (MBC-P) questionnaire to assess the value of progression-free survival for women with metastatic breast cancer. Breast Cancer Res Treat. 2013; 142: 603-9. doi: 10.1007/s10549-013-2734-4.

6. Khan MI, Adhami VM, Lall RK, Sechi M, Joshi DC, Haidar OM, Syed DN, Siddiqui IA, Chiu SY, Mukhtar H. YB-1 expression promotes epithelial-to-mesenchymal transition in prostate cancer that is inhibited by a small molecule fisetin. Oncotarget. 2014; 5: 2462-74. doi: 10.18632/oncotarget.1790.

7. Chaffer CL, Weinberg RA. A perspective on cancer cell metastasis. Science. 2011; 331: 1559-64. doi: 10.1126/ science. 1203543.

8. Weinberg RA. (2007). The Biology of Cancer. (New York: Garland Science).

9. Krasnapolski MA, Todaro LB, de Kier Joffe EB. Is the epithelial-to-mesenchymal transition clinically relevant for the cancer patient? Curr Pharm Biotechnol. 2011; 12: 1891-9.

10. Lamouille S, Xu J, Derynck R. Molecular mechanisms of epithelial-mesenchymal transition. Nat Rev Mol Cell Biol. 2014; 15: 178-96. doi: 10.1038/nrm3758.

11. Khan MA, Chen HC, Zhang D, Fu J. Twist: a molecular target in cancer therapeutics. Tumour Biol. 2013; 34: 2497 506. doi: 10.1007/s13277-013-1002-x.

12. Peinado H, Olmeda D, Cano A. Snail, Zeb and bHLH factors in tumour progression: an alliance against the epithelial phenotype? Nat Rev Cancer. 2007; 7: 415-28. doi: 10.1038/nrc2131.

13. Li L, Li W. Epithelial-mesenchymal transition in human cancer: comprehensive reprogramming of metabolism, epigenetics, and differentiation. Pharmacol Ther. 2015; 150: 33-46. doi: 10.1016/j.pharmthera.2015.01.004.

14. Imani $\mathrm{S}$, Hosseinifard $\mathrm{H}$, Cheng J, Wei C, Fu J. Prognostic Value of EMT-inducing Transcription Factors (EMT-TFs) in Metastatic Breast Cancer: A Systematic Review and Metaanalysis. Sci Rep. 2016; 6: 28587. doi: 10.1038/srep28587.

15. Yang J, Mani SA, Donaher JL, Ramaswamy S, Itzykson RA, Come C, Savagner P, Gitelman I, Richardson A, Weinberg RA. Twist, a master regulator of morphogenesis, plays an essential role in tumor metastasis. Cell. 2004; 117 : 927-39. doi: 10.1016/j.cell.2004.06.006.
16. Mironchik Y, Winnard PT, Jr., Vesuna F, Kato Y, Wildes F, Pathak AP, Kominsky S, Artemov D, Bhujwalla Z, Van Diest P, Burger H, Glackin C, Raman V. Twist overexpression induces in vivo angiogenesis and correlates with chromosomal instability in breast cancer. Cancer Res. 2005; 65: 10801-9. doi: 10.1158/0008-5472.CAN-05-0712.

17. Teng Y, Mei Y, Hawthorn L, Cowell JK. WASF3 regulates miR-200 inactivation by ZEB1 through suppression of KISS1 leading to increased invasiveness in breast cancer cells. Oncogene. 2014; 33: 203-11. doi: 10.1038/ onc.2012.565.

18. Weyemi U, Redon CE, Sethi TK, Burrell AS, Jailwala P, Kasoji M, Abrams N, Merchant A, Bonner WM. Twist1 and Slug mediate H2AX-regulated epithelial-mesenchymal transition in breast cells. Cell Cycle. 2016; 15: 2398-404. doi: 10.1080/15384101.2016.1198864.

19. Misso G, Di Martino MT, De Rosa G, Farooqi AA, Lombardi A, Campani V, Zarone MR, Gulla A, Tagliaferri P, Tassone P, Caraglia M. Mir-34: a new weapon against cancer? Mol Ther Nucleic Acids. 2014; 3: e194. doi: 10.1038/mtna.2014.47.

20. Hermeking $H$. The miR-34 family in cancer and apoptosis. Cell Death Differ. 2010; 17: 193-9. doi: 10.1038/ cdd.2009.56.

21. Mlcochova H, Machackova T, Rabien A, Radova L, Fabian P, Iliev R, Slaba K, Poprach A, Kilic E, Stanik M, Redova-Lojova M, Svoboda M, Dolezel J, et al. Epithelialmesenchymal transition-associated microRNA/mRNA signature is linked to metastasis and prognosis in clear-cell renal cell carcinoma. Sci Rep. 2016; 6: 31852. doi: 10.1038/ srep31852.

22. Pang RT, Leung CO, Ye TM, Liu W, Chiu PC, Lam KK, Lee KF, Yeung WS. MicroRNA-34a suppresses invasion through downregulation of Notch1 and Jagged1 in cervical carcinoma and choriocarcinoma cells. Carcinogenesis. 2010; 31: 1037-44. doi: 10.1093/carcin/bgq066.

23. Shao C, Zhang J, Fu J, Ling F. The potential role of Brachyury in inducing epithelial-to-mesenchymal transition (EMT) and HIF-1alpha expression in breast cancer cells. Biochem Biophys Res Commun. 2015; 467: 1083-9. doi: 10.1016/j.bbrc.2015.09.076.

24. Yang P, Li QJ, Feng Y, Zhang Y, Markowitz GJ, Ning S, Deng Y, Zhao J, Jiang S, Yuan Y, Wang HY, Cheng SQ, Xie D, et al. TGF-beta-miR-34a-CCL22 signaling-induced Treg cell recruitment promotes venous metastases of HBVpositive hepatocellular carcinoma. Cancer Cell. 2012; 22: 291-303. doi: 10.1016/j.ccr.2012.07.023.

25. Pang MF, Georgoudaki AM, Lambut L, Johansson J, Tabor V, Hagikura K, Jin Y, Jansson M, Alexander JS, Nelson CM, Jakobsson L, Betsholtz C, Sund M, et al. TGF-beta1induced EMT promotes targeted migration of breast cancer cells through the lymphatic system by the activation of CCR7/CCL21-mediated chemotaxis. Oncogene. 2016; 35: 748-60. doi: 10.1038/onc.2015.133. 
26. Wushou A, Hou J, Zhao YJ, Shao ZM. Twist-1 up-regulation in carcinoma correlates to poor survival. Int J Mol Sci. 2014; 15: 21621-30. doi: 10.3390/ijms151221621.

27. Kim T, Veronese A, Pichiorri F, Lee TJ, Jeon YJ, Volinia S, Pineau P, Marchio A, Palatini J, Suh SS, Alder H, Liu CG, Dejean A, et al. p53 regulates epithelial-mesenchymal transition through microRNAs targeting ZEB1 and ZEB2. J Exp Med. 2011; 208: 875-83. doi: 10.1084/jem.20110235.

28. Yang L, Hou Y, Yuan J, Tang S, Zhang H, Zhu Q, Du YE, Zhou M, Wen S, Xu L, Tang X, Cui X, Liu M. Twist promotes reprogramming of glucose metabolism in breast cancer cells through PI3K/AKT and p53 signaling pathways. Oncotarget. 2015; 6: 25755-69. doi: 10.18632/ oncotarget.4697.

29. Storci G, Sansone P, Mari S, D'Uva G, Tavolari S, Guarnieri T, Taffurelli M, Ceccarelli C, Santini D, Chieco P, Marcu KB, Bonafe M. TNFalpha up-regulates SLUG via the NF-kappaB/HIF1alpha axis, which imparts breast cancer cells with a stem cell-like phenotype. J Cell Physiol. 2010; 225: 682-91. doi: 10.1002/jcp.22264.

30. Si W, Li Y, Shao H, Hu R, Wang W, Zhang K, Yang Q. MiR34a Inhibits Breast Cancer Proliferation and Progression by Targeting Wnt1 in Wnt/beta-Catenin Signaling Pathway. Am J Med Sci. 2016; 352: 191-9. doi: 10.1016/j. amjms.2016.05.002.

31. Mansoori B, Mohammadi A, Shirjang S, Baghbani E, Baradaran B. Micro RNA 34a and Let-7a Expression in Human Breast Cancers is Associated with Apoptotic Expression Genes. Asian Pac J Cancer Prev. 2016; 17: 1887-90.

32. Adams BD, Wali VB, Cheng CJ, Inukai S, Booth CJ, Agarwal S, Rimm DL, Gyorffy B, Santarpia L, Pusztai L, Saltzman WM, Slack FJ. miR-34a Silences c-SRC to Attenuate Tumor Growth in Triple-Negative Breast Cancer. Cancer Res. 2016; 76: 927-39. 10.1158/0008-5472. CAN-15-2321.

33. Kang L, Mao J, Tao Y, Song B, Ma W, Lu Y, Zhao L, Li J, Yang B, Li L. MicroRNA-34a suppresses the breast cancer stem cell-like characteristics by downregulating Notch1 pathway. Cancer Sci. 2015; 106: 700-8. doi: 10.1111/ cas. 12656.

34. Gyorffy B, Lanczky A, Eklund AC, Denkert C, Budczies J, Li Q, Szallasi Z. An online survival analysis tool to rapidly assess the effect of 22,277 genes on breast cancer prognosis using microarray data of 1,809 patients. Breast Cancer Res Treat. 2010; 123: 725-31. doi: 10.1007/s10549-009-0674-9.

35. Khan MA, Tania M, Wei C, Mei Z, Fu S, Cheng J, Xu $\mathrm{J}, \mathrm{Fu}$ J. Thymoquinone inhibits cancer metastasis by downregulating TWIST1 expression to reduce epithelial to mesenchymal transition. Oncotarget. 2015; 6: 19580-91. doi: 10.18632/oncotarget.3973.

36. Haynes J, Srivastava J, Madson N, Wittmann T, Barber DL. Dynamic actin remodeling during epithelial-mesenchymal transition depends on increased moesin expression.
Mol Biol Cell. 2011; 22: 4750-64. doi: 10.1091/mbc. E11-02-0119.

37. Hansen SM, Berezin V, Bock E. Signaling mechanisms of neurite outgrowth induced by the cell adhesion molecules NCAM and N-cadherin. Cell Mol Life Sci. 2008; 65: 380921. doi: 10.1007/s00018-008-8290-0.

38. Prosperi JR, Goss KH. A Wnt-ow of opportunity: targeting the Wnt/beta-catenin pathway in breast cancer. Curr Drug Targets. 2010; 11: 1074-88.

39. Khramtsov AI, Khramtsova GF, Tretiakova M, Huo D, Olopade OI, Goss KH. Wnt/beta-catenin pathway activation is enriched in basal-like breast cancers and predicts poor outcome. Am J Pathol. 2010; 176: 2911-20. doi: 10.2353/ ajpath.2010.091125.

40. Liu T, Hu K, Zhao Z, Chen G, Ou X, Zhang H, Zhang $X$, Wei X, Wang D, Cui M, Liu C. MicroRNA-1 down-regulates proliferation and migration of breast cancer stem cells by inhibiting the Wnt/beta-catenin pathway. Oncotarget. 2015; 6: 41638-49. doi: 10.18632/ oncotarget.5873.

41. Yang S, Li Y, Gao J, Zhang T, Li S, Luo A, Chen H, Ding F, Wang X, Liu Z. MicroRNA-34 suppresses breast cancer invasion and metastasis by directly targeting Fra-1. Oncogene. 2013; 32: 4294-303. doi: 10.1038/onc.2012.432.

42. Zhao G, Guo J, Li D, Jia C, Yin W, Sun R, Lv Z, Cong X. MicroRNA-34a suppresses cell proliferation by targeting LMTK3 in human breast cancer mcf-7 cell line. DNA Cell Biol. 2013; 32: 699-707. doi: 10.1089/dna.2013.2130.

43. Jiang Q, He M, Guan S, Ma M, Wu H, Yu Z, Jiang L, Wang Y, Zong X, Jin F, Wei M. MicroRNA-100 suppresses the migration and invasion of breast cancer cells by targeting FZD-8 and inhibiting Wnt/beta-catenin signaling pathway. Tumour Biol. 2016; 37: 5001-11. doi: 10.1007/ s13277-015-4342-x.

44. Hong L, Pan F, Jiang H, Zhang L, Liu Y, Cai C, Hua C, Luo X, Sun J, Chen Z. miR-125b inhibited epithelialmesenchymal transition of triple-negative breast cancer by targeting MAP2K7. Onco Targets Ther. 2016; 9: 2639-48. doi: 10.2147/OTT.S102713.

45. Isobe T, Hisamori S, Hogan DJ, Zabala M, Hendrickson DG, Dalerba P, Cai S, Scheeren F, Kuo AH, Sikandar SS, Lam JS, Qian D, Dirbas FM, et al. miR-142 regulates the tumorigenicity of human breast cancer stem cells through the canonical WNT signaling pathway. Elife. 2014; 3. doi: 10.7554/eLife.01977.

46. Peng F, Xiong L, Tang H, Peng C, Chen J. Regulation of epithelial-mesenchymal transition through microRNAs: clinical and biological significance of microRNAs in breast cancer. Tumour Biol. 2016. doi: 10.1007/ s13277-016-5334-1.

47. Nalls D, Tang SN, Rodova M, Srivastava RK, Shankar S. Targeting epigenetic regulation of miR-34a for treatment of pancreatic cancer by inhibition of pancreatic cancer stem 
cells. PLoS One. 2011; 6: e24099. doi: 10.1371/journal. pone.0024099.

48. Roy S, Levi E, Majumdar AP, Sarkar FH. Expression of miR-34 is lost in colon cancer which can be re-expressed by a novel agent CDF. J Hematol Oncol. 2012; 5: 58. doi: 10.1186/1756-8722-5-58.

49. Yu G, Li H, Wang J, Gumireddy K, Li A, Yao W, Tang K, Xiao W, Hu J, Xiao H, Lang B, Ye Z, Huang Q, et al. miRNA-34a suppresses cell proliferation and metastasis by targeting CD44 in human renal carcinoma cells. J Urol. 2014; 192: 1229-37. doi: 10.1016/j.juro.2014.05.094.

50. Wu H, Huang M, Liu Y, Shu Y, Liu P. Luteolin Induces Apoptosis by Up-regulating miR-34a in Human Gastric Cancer Cells. Technol Cancer Res Treat. 2015; 14: 747-55. doi: $10.7785 /$ tcrt.2012.500434.

51. Javeri A, Ghaffarpour M, Taha MF, Houshmand $M$. Downregulation of miR-34a in breast tumors is not associated with either p53 mutations or promoter hypermethylation while it correlates with metastasis. Med Oncol. 2013; 30: 413. doi: 10.1007/s12032-012-0413-7.

52. Lodygin D, Tarasov V, Epanchintsev A, Berking C, Knyazeva T, Korner H, Knyazev P, Diebold J, Hermeking $\mathrm{H}$. Inactivation of miR-34a by aberrant $\mathrm{CpG}$ methylation in multiple types of cancer. Cell Cycle. 2008; 7: 2591-600. doi: $10.4161 /$ cc.7.16.6533.

53. Stankevicins L, Almeida da Silva AP, Ventura Dos Passos F, Dos Santos Ferreira E, Menks Ribeiro MC, G David M, J Pires E, Ferreira-Machado SC, Vassetzky Y, de Almeida $\mathrm{CE}$, de Moura Gallo CV. MiR-34a is up-regulated in response to low dose, low energy X-ray induced DNA damage in breast cells. Radiat Oncol. 2013; 8: 231. doi: 10.1186/1748-717X-8-231.

54. Barbashina V, Salazar P, Holland EC, Rosenblum MK, Ladanyi M. Allelic losses at 1p36 and 19q13 in gliomas: correlation with histologic classification, definition of a $150-\mathrm{kb}$ minimal deleted region on $1 \mathrm{p} 36$, and evaluation of CAMTA1 as a candidate tumor suppressor gene. Clin Cancer Res. 2005; 11: 1119-28.

55. Li L, Yuan L, Luo J, Gao J, Guo J, Xie X. MiR-34a inhibits proliferation and migration of breast cancer through downregulation of Bcl-2 and SIRT1. Clin Exp Med. 2013; 13: 109-17. doi: 10.1007/s10238-012-0186-5.

56. Kefas B, Comeau L, Floyd DH, Seleverstov O, Godlewski J, Schmittgen T, Jiang J, diPierro CG, Li Y, Chiocca EA, Lee J, Fine H, Abounader R, et al. The neuronal microRNA miR-326 acts in a feedback loop with notch and has therapeutic potential against brain tumors. J Neurosci. 2009; 29: 15161-8. doi: 10.1523/JNEUROSCI.4966-09.2009.

57. Sun L, Fang J. Epigenetic regulation of epithelialmesenchymal transition. Cell Mol Life Sci. 2016; 73: 4493 515. doi: 10.1007/s00018-016-2303-1.

58. Avtanski DB, Nagalingam A, Kuppusamy P, Bonner MY, Arbiser JL, Saxena NK, Sharma D. Honokiol abrogates leptin-induced tumor progression by inhibiting
Wnt1-MTA1-beta-catenin signaling axis in a microRNA34a dependent manner. Oncotarget. 2015; 6: 16396-410. doi: 10.18632/oncotarget.3844.

59. Johansson J, Berg T, Kurzejamska E, Pang MF, Tabor V, Jansson M, Roswall P, Pietras K, Sund M, Religa P, Fuxe J. MiR-155-mediated loss of C/EBPbeta shifts the TGF-beta response from growth inhibition to epithelial-mesenchymal transition, invasion and metastasis in breast cancer. Oncogene. 2013; 32: 5614-24. doi: 10.1038/onc.2013.322.

60. Ahn YH, Gibbons DL, Chakravarti D, Creighton CJ, Rizvi ZH, Adams HP, Pertsemlidis A, Gregory PA, Wright JA, Goodall GJ, Flores ER, Kurie JM. ZEB1 drives prometastatic actin cytoskeletal remodeling by downregulating miR-34a expression. J Clin Invest. 2012; 122: 3170-83. doi: 10.1172/JCI63608.

61. Yang J, Kuang XR, Lv PT, Yan XX. Thymoquinone inhibits proliferation and invasion of human nonsmall-cell lung cancer cells via ERK pathway. Tumour Biol. 2015; 36: 25969. doi: 10.1007/s13277-014-2628-z.

62. Abdelfadil E, Cheng YH, Bau DT, Ting WJ, Chen LM, Hsu HH, Lin YM, Chen RJ, Tsai FJ, Tsai CH, Huang CY. Thymoquinone induces apoptosis in oral cancer cells through p38beta inhibition. Am J Chin Med. 2013; 41: 68396. doi: 10.1142/S0192415X1350047X.

63. Peng L, Liu A, Shen Y, Xu HZ, Yang SZ, Ying XZ, Liao W, Liu HX, Lin ZQ, Chen QY, Cheng SW, Shen WD. Antitumor and anti-angiogenesis effects of thymoquinone on osteosarcoma through the NF-kappaB pathway. Oncol Rep. 2013; 29: 571-8. doi: 10.3892/or.2012.2165.

64. Huang RY, Wong MK, Tan TZ, Kuay KT, Ng AH, Chung VY, Chu YS, Matsumura N, Lai HC, Lee YF, Sim WJ, Chai C, Pietschmann E, et al. An EMT spectrum defines an anoikis-resistant and spheroidogenic intermediate mesenchymal state that is sensitive to e-cadherin restoration by a src-kinase inhibitor, saracatinib (AZD0530). Cell Death Dis. 2013; 4: e915. doi: 10.1038/cddis.2013.442.

65. Bhattacharya S, Ahir M, Patra P, Mukherjee S, Ghosh S, Mazumdar M, Chattopadhyay S, Das T, Chattopadhyay D, Adhikary A. PEGylated-thymoquinone-nanoparticle mediated retardation of breast cancer cell migration by deregulation of cytoskeletal actin polymerization through miR-34a. Biomaterials. 2015; 51: 91-107. doi: 10.1016/j. biomaterials.2015.01.007.

66. Khan MA, Chen HC, Tania M, Zhang DZ. Anticancer activities of Nigella sativa (black cumin). Afr J Tradit Complement Altern Med. 2011; 8: 226-32. doi: 10.4314/ ajtcam.v8i5S.10.

67. Woo CC, Hsu A, Kumar AP, Sethi G, Tan KH. Thymoquinone inhibits tumor growth and induces apoptosis in a breast cancer xenograft mouse model: the role of $\mathrm{p} 38$ MAPK and ROS. PLoS One. 2013; 8: e75356. doi: 10.1371/ journal.pone.0075356.

68. Rajput S, Kumar BN, Dey KK, Pal I, Parekh A, Mandal $\mathrm{M}$. Molecular targeting of Akt by thymoquinone promotes 
G(1) arrest through translation inhibition of cyclin D1 and induces apoptosis in breast cancer cells. Life Sci. 2013; 93: 783-90. doi: 10.1016/j.lfs.2013.09.009.

69. Ke X, Zhao Y, Lu X, Wang Z, Liu Y, Ren M, Lu G, Zhang D, Sun Z, Xu Z, Song JH, Cheng Y, Meltzer SJ, et al. TQ inhibits hepatocellular carcinoma growth in vitro and in vivo via repression of Notch signaling. Oncotarget. 2015; 6: 32610-21. doi: 10.18632/oncotarget.5362.

70. Zhu WQ, Wang J, Guo XF, Liu Z, Dong WG. Thymoquinone inhibits proliferation in gastric cancer via the STAT3 pathway in vivo and in vitro. World J Gastroenterol. 2016; 22: 4149-59. doi: 10.3748/wjg.v22. i16.4149.

71. Mu GG, Zhang LL, Li HY, Liao Y, Yu HG. Thymoquinone Pretreatment Overcomes the Insensitivity and Potentiates the Antitumor Effect of Gemcitabine Through Abrogation of Notch1, PI3K/Akt/mTOR Regulated Signaling Pathways in Pancreatic Cancer. Dig Dis Sci. 2015; 60: 1067-80. doi: 10.1007/s10620-014-3394-x.

72. Wei C, Cheng J, Zhou B, Zhu L, Khan MA, He T, Zhou S, He J, Lu X, Chen H, Zhang D, Zhao Y, Fu J. Tripartite motif containing 28 (TRIM28) promotes breast cancer metastasis by stabilizing TWIST1 protein. Sci Rep. 2016; 6: 29822. doi: $10.1038 /$ srep29822.
73. Li Y, Guessous F, Zhang Y, Dipierro C, Kefas B, Johnson E, Marcinkiewicz L, Jiang J, Yang Y, Schmittgen TD, Lopes B, Schiff D, Purow B, et al. MicroRNA-34a inhibits glioblastoma growth by targeting multiple oncogenes. Cancer Res. 2009; 69: 7569-76. doi: 10.1158/0008-5472. CAN-09-0529.

74. Zhang L, Yang M, Gan L, He T, Xiao X, Stewart MD, Liu X, Yang L, Zhang T, Zhao Y, Fu J. DLX4 upregulates TWIST and enhances tumor migration, invasion and metastasis. Int J Biol Sci. 2012; 8: 1178-87. doi: 10.7150/ ijbs. 4458 .

75. Khan MA, Zhu L, Tania M, Xiao XL, Fu JJ. Relationship between SPOP mutation and breast cancer in Chinese population. Genet Mol Res. 2015; 14: 12362-6. doi: 10.4238/2015.October.16.2.

76. Cheng J, Fu S, Wei C, Tania M, Khan MA, Imani S, Zhou B, Chen H, Xiao X, Wu J, Fu J. Evaluation of PIK3CA mutations as a biomarker in Chinese breast carcinomas from Western China. Cancer Biomark. 2017; In Press.

77. Fu J, Qin L, He T, Qin J, Hong J, Wong J, Liao L, Xu J. The TWIST/Mi2/NuRD protein complex and its essential role in cancer metastasis. Cell Res. 2011; 21: 275-89. doi: 10.1038/cr.2010.118. 